NBER WORKING PAPER SERIES

\title{
ESTIMATING LOST OUTPUT FROM ALLOCATIVE INEFFICIENCY, WITH AN APPLICATION TO CHILE AND FIRING COSTS
}

\author{
Amil Petrin \\ Jagadeesh Sivadasan \\ Working Paper 17373 \\ http://www.nber.org/papers/w17373
NATIONAL BUREAU OF ECONOMIC RESEARCH
1050 Massachusetts Avenue
Cambridge, MA 02138

August 2011

We thank the editor and an anonymous referee for detailed comments and suggestions. We have benefited from discussions with and thank (without implicating for any remaining errors) Susanto Basu, Alejandra Cox-Edwards, James Heckman, Gunter Hitsch, Wendy Petropoulos and Jeremy Fox. We also thank seminar participants at the University of Chicago, Montana State University, Yale University, University of Minnesota, University of Michigan, IADB, NBER Productivity Group, the COST workshop and ASSA meetings. We thank Esteban Puentes for facilitating access to the Social Protection Survey data. The views expressed herein are those of the authors and do not necessarily reflect the views of the National Bureau of Economic Research.

NBER working papers are circulated for discussion and comment purposes. They have not been peerreviewed or been subject to the review by the NBER Board of Directors that accompanies official NBER publications.

(C) 2011 by Amil Petrin and Jagadeesh Sivadasan. All rights reserved. Short sections of text, not to exceed two paragraphs, may be quoted without explicit permission provided that full credit, including (C) notice, is given to the source. 
Estimating Lost Output from Allocative Inefficiency, with an Application to Chile and Firing Costs

Amil Petrin and Jagadeesh Sivadasan

NBER Working Paper No. 17373

August 2011

JEL No. D24,J65,O47,O54

\begin{abstract}
We propose a new measure of allocative efficiency based on unrealized increases in aggregate productivity growth. We show that the difference in the value of the marginal product of an input and its marginal cost at any plant - the plant-input "gap" - is exactly equal to the change in aggregate output that would occur if that plant changed that input's use by one unit. The mean absolute gap across plants for any input can then be interpreted as an approximation to the gain to society that would occur if every plant had a one-unit change in that input in the efficient direction, holding everything else constant. We show how to estimate this average gap using plant-level data for 1982-1994 from Chilean manufacturing, a sector largely viewed as being one of South America's least distorted. We find the gaps for blue and white collar labor are quite large in absolute value and imply that a one-unit move in the correct direction for blue collar would increase aggregate value added by almost $0.5 \%$. We also find that the gaps for blue and white collar workers are increasing over time while the gaps for materials and electricity are not. The timing of the two separate increases in firing costs and the sharpest increases in the labor gaps is suggestive that the increases in average within-firm labor gaps may be related to the increases in severance pay.
\end{abstract}

\author{
Amil Petrin \\ Department of Economics \\ University of Minnesota \\ 4-101 Hanson Hall \\ Minneapolis, MN 55455 \\ and NBER \\ petrin@umn.edu \\ Jagadeesh Sivadasan \\ University of Michigan \\ Ross School of Business \\ 701 Tappan, Room R4310 \\ Ann Arbor, MI 48103 \\ jagadees@umich.edu
}




\title{
Estimating Lost Output from Allocative Inefficiency, with an Application to Chile and Firing Costs*
}

\author{
Amil Petrin \\ University of Minnesota and NBER ${ }^{\dagger} \quad$ University of Michigan ${ }^{\ddagger}$ \\ Jagadeesh Sivadasan
}

August 2011

\begin{abstract}
We propose a new measure of allocative efficiency based on unrealized increases in aggregate productivity growth. We show that the difference in the value of the marginal product of an input and its marginal cost at any plant - the plant-input "gap" - is exactly equal to the change in aggregate output that would occur if that plant changed that input's use by one unit. The mean absolute gap across plants for any input can then be interpreted as an approximation to the gain to society that would occur if every plant had a one-unit change in that input in the efficient direction, holding everything else constant. We show how to estimate this average gap using plant-level data for 1982-1994 from Chilean manufacturing, a sector largely viewed as being one of South America's least distorted. We find the gaps for blue and white collar labor are quite large in absolute value and imply that a one-unit move in the correct direction for blue collar would increase aggregate value added by almost $0.5 \%$. We also find that the gaps for blue and white collar workers are increasing over time while the gaps for materials and electricity are not. The timing of the two separate increases in firing costs and the sharpest increases in the labor gaps is suggestive that the increases in average within-firm labor gaps may be related to the increases in severance pay.
\end{abstract}

JEL codes: D24, J65, 047, 054

${ }^{*}$ We thank the editor and an anonymous referee for detailed comments and suggestions. We have benefitted from discussions with and thank (without implicating for any remaining errors) Susanto Basu, Alejandra Cox-Edwards, James Heckman, Gunter Hitsch, Wendy Petropoulos and Jeremy Fox. We also thank seminar participants at the University of Chicago, Montana State University, Yale University, University of Minnesota, University of Michigan, IADB, NBER Productivity Group, the COST workshop and ASSA meetings. We thank Esteban Puentes for facilitating access to the Social Protection Survey data.

†email: petrin@umn.edu

‡email: jagadees@umich.edu 


\section{Introduction}

There are many phenomena that move an economy away from the neoclassical setup where an input's value of marginal product is equated with its marginal cost. These include markups, hiring, firing and search costs, capital adjustment costs, taxes and subsidies, holdup and other contracting problems, and non-optimal managerial behavior. We develop a simple approach that uses production data to estimate the "gaps" between an input's marginal product and its cost and use them to infer the value of lost output arising from allocative inefficiency.

We characterize allocative efficiency in terms of its impact on aggregate productivity growth (APG), defined as the change in aggregate final demand minus the change in aggregate expenditures on labor and capital. Under this definition of APG, Petrin and Levinsohn (2011) show that a unit increase in any input raises APG by that input's concurrent value of marginal product-input cost gap. With common input costs across firms, aggregate output increases holding aggregate input use constant if inputs are reallocated from lower to higher marginal value activities. As an indicator of allocative inefficiency, we look at the potential gain from additional adjustments in inputs that do not occur.

The gaps are the principal input into our calculation of lost output from allocative inefficiency. We show how plant-level or industry-level production data identifies the net output change when a unit of labor (e.g.) is reallocated from one establishment to another, or from being unemployed to being employed. We provide a framework for evaluating policy changes that affect these plant-level gaps, like increases in hiring or firing costs.

Our approach can readily be carried out in standard programming packages. Our estimates for the value of marginal products use estimates from production functions, for which there are a wide variety of estimators.1 Production data also typically contains measurements on input expenditures, and we use these to approximate the marginal cost of each input.

Our approach to measuring allocative inefficiency is closest in spirit to Hsieh and Klenow (2009) and is also related to the wide collection of definitions of reallocation from Basu and Fernald (2002) and from Baily, Hulten and Campbell (1992) (BHC) and its derivatives (e.g. Olley and Pakes, (1996), and Foster, Haltiwanger and Krizan 2001). The main difference between our definition of reallocation and all of these variants is that they are not based on definitions of APG that equal the change in final demand minus the change in expenditures on labor and capital.

\footnotetext{
${ }^{1}$ Our Stata code, which is available at the authors' websites, contains three different estimation approaches for production functions and illustrates how to construct estimate of the gaps from them.
} 
This weakens their link to the theory literature on reallocation and growth (see e.g. Aghion and Howitt (1992) or Caballero and Hammour (1996) and the large literature that has followed). A second important difference with some of these alternative approaches is that we avoid the use of cost shares to estimate production function parameters or markups because the theory that motivates doing so does not hold when the cost function is not differentiable, as in any s-S type setting like a world with adjustment costs for labor or capital. ${ }^{2}$

We illustrate our approach using plant-level data from 1982-1994 in Chile, one of Latin America's fastest growing countries in the late 80s and 90s. Many economists have attributed Chile's economic growth to the measures taken in the 1970s to reduce economic frictions. We look at the magnitudes of gaps at Chilean manufacturing firms across the period 1982-1996. While we find negligible gaps for materials across estimators and small gaps for electricity inputs, we find large gaps for blue and white collar labor inputs. On average, the gaps for labor equal approximately one year's salary for both blue and white collar. The finding implies that increasing labor by one unit at firms with positive gaps and decreasing labor by one unit at firms with negative gaps leads to an increase in value added of $0.5 \%$.

We then look for an impact on allocative efficiency of two increases in the cost of dismissing workers ${ }^{3}$ In 1984, Chile no longer exempted firms from severance pay when they could demonstrate "economic cause" for dismissal. Severance was set equal to no less than a month's wages per year of tenure, with a five month ceiling. In 1991 the ceiling increased to 11 months. We look at the gaps for blue and white collar labor right before and after the two policy changes. We find increases in the mean of within-firm gaps following increases in firing costs for both blue and white collar labor. All years after 1985 have average blue and white-collar gaps that are significantly different from every year prior to 1985, and the biggest jump in the gaps occurs right after the first increase in firing costs.

Economic theory says that a variety of changes can impact plant-level gaps and

\footnotetext{
${ }^{2}$ See Bentolila and Bertola (1990) who provide evidence of non-differentiable adjustment costs for labor and also Caballero and Engel (1993) and Caballero and Engel (1999) who provide similar evidence for capital. See also the discussion in Bond and Van Reenen (2007).

${ }^{3}$ Most of the empirical work on firing costs focuses on whether employment levels increase or decrease (see Heckman and Pages (2004)). The evidence has largely been mixed, probably because the theory says that firing costs, when they do have an impact, lead some firms to hold too much labor and others to hold too little. Depending upon the assumptions, some theory papers find a positive effect of increasing firing costs on employment (Bentolila and Bertola (1990), Alvarez and Veracierto (2001)), while others find a negative effect (Risager and Sorensen (1997), Bertola (1990), and Hopenhayn and Rogerson (1993)). Both Edwards and Edwards (2000), who use aggregate time-series data, and Pages and Montenegro (1999), who use individual-level employment survey data, find no effect of these increases on aggregate unemployment levels.
} 
we try to isolate the impact of firing costs from other changes occurring in the economy. We show that different policies can have implications for gaps that vary across inputs and one can use these differences to try to isolate the impact of a policy change on allocative efficiency. Lemma 2 provides one result, showing that policies that impact adjustment costs for inputs like labor or capital only affect the marginal revenue product (MRP) gaps associated with those inputs. Inputs without adjustment costs should not have their gaps change, so these inputs can act as controls in the spirit of a difference-in-differences approach to identification.

We then look at the MRP gaps for materials and electricity right before and after the policy change. We find no evidence of any increase in the gaps for either materials or electricity across the time periods. In summary, our approach identifies a significant fall in allocative efficiency for both blue and white collar labor in the 1980s, and both the timing of the gap changes and the fact that "freely variable" inputs did not experience MRP gap changes suggest at least part of the decrease in allocative efficiency may have occurred because of the increase in firing costs.

We undertake a series of checks to test the robustness of our results. 4 In particular, we examine robustness to: (i) using two alternative production functions; (ii) using an alternative definition of the productivity residual; (iii) using two tests to address potential measurement error in wages; (iv) using a sample-split test based on excess turnover rates (to see if industries with greater voluntary turnover are less affected by increases in job security); (iv) differences in industry unionization rates (to control for changes in bargaining environment that would likely impact unionized industry more strongly); (v) using an alternative deflator for nominal gaps; and (vi) exclusion of entrants and exiters. Our main findings are robust to all of these checks. We also check and find that the gaps are correlated with probability of exit.

The paper proceeds as follows. Sections 2-4 develop the reallocation framework and estimation methodology. Section 5 summarizes the key economic reforms in Chile over the period that we examine (1982-1996). Section 6 describes the plantlevel data. Section 7 provide details of estimation, and Section 8 presents the baseline results and robustness checks. Section 9 concludes.

\footnotetext{
${ }^{4}$ We thank an anonymous referee for suggesting or prompting a number of these tests.
} 


\section{Measuring Lost Output Due to Allocative Inefficiency}

We use the accounting framework from Petrin and Levinsohn (2011) to derive aggregate productivity growth from the micro-level and derive the reallocation terms. Readers not interested in the details can skip to Section 2.1 and then directly to implementation in Section 4.

We assume there are at most $N$ plants in the economy each of which produces one good $5^{5}$ Each plant $i$ 's production technology is given by

$$
Q^{i}\left(X_{i}, M_{i}, \omega_{i}\right)
$$

where $X_{i}=\left(X_{i 1}, \ldots, X_{i K}\right)$ is the vector of $\mathrm{K}$ primary input amounts (types of labor and capital) used at plant $i, M_{i}=\left(M_{i 1}, \ldots, M_{i J}\right)$ is the vector giving the amount of each plant $j$ 's output used as an intermediate input at plant $i$, and $\omega_{i}$ is the level of plant $i$ 's technical efficiency. $F_{i}$ is equal to the sum of all fixed and sunk costs at $i$, and we normalize these costs to the equivalent of the forgone output and deduct them, letting $Q_{i}=Q^{i}\left(X_{i}, M_{i}, \omega_{i}\right)-F_{i}$. The total amount of output from plant $i$ that goes to final demand $Y_{i}$ is then

$$
Y_{i}=Q_{i}-\sum_{j} M_{j i}
$$

where $\sum_{j} M_{j i}$ is the total amount of $i$ 's output that serves as intermediate input within the plant and at other plants.

We operate in continuous time (suppressing $t$ ), so the differential for $i$ 's final demand is given as $d Y_{i}=d Q_{i}-\sum_{j} d M_{i j}$. Letting $P_{i}$ denote the price of plant i's output, aggregate productivity growth (APG) is the difference between the change in aggregate final demand and the change in aggregate costs:

$$
P L \equiv \sum_{i} P_{i} d Y_{i}-\sum_{i} \sum_{k} W_{i k} d X_{i k}
$$

where $W_{i k}$ equals the unit cost to $i$ of the $k^{\text {th }}$ primary input and $d X_{i k}$ is the change in the use of that primary input at plant $i$, and the summation is taken over all plants.6

\footnotetext{
${ }^{5}$ Any of the $\mathrm{N}$ products may potentially be used as an input in production. The setup extends to multi-product plants.

${ }^{6}$ In the general setup from Petrin and Levinsohn (2011) the path of primary and intermediate inputs and productivity shocks for firm $i$ is given as $Z_{i t}=\left(X_{i t}, M_{i t}, \omega_{i t}\right), t \in[0,1]$. For the entire economy they write $Z_{t}=\left(Z_{1 t}, Z_{2 t}, \ldots, Z_{N t}\right)$. Given $Z_{t}$, output quantities are determined by the production technologies and $Q_{t}=\left(Q_{1 t}\left(Z_{1 t}\right), \ldots, Q_{N t}\left(Z_{N t}\right)\right)$. Prices are assumed to be uniquely determined by $Q_{t}$, given as $P_{t}=\left(P_{1 t}\left(Q_{t}\right), \ldots, P_{N t}\left(Q_{t}\right)\right)$, and similarly for primary input costs $\left.W_{t}=\left(W_{1 t}\left(Z_{t}\right), \ldots, W_{K t}\left(Z_{t}\right)\right)\right)$. Fixed and sunk costs for all $i$ are deterministic given $Z_{t}$ and its past values, and the vector of fixed costs is given as $F_{t}=\left(F_{1 t}, \ldots, F_{N t}\right) . Y_{i t}$ can then be directly calculated for all $i$ and $t \in[0,1]$.
} 
When $Q_{i}$ is differentiable equation (2) can be decomposed as follows:

$$
\sum_{i} \sum_{k}\left(P_{i} \frac{\partial Q_{i}}{\partial X_{k}}-W_{i k}\right) d X_{i k}+\sum_{i} \sum_{j}\left(P_{i} \frac{\partial Q_{i}}{\partial M_{j}}-P_{j}\right) d M_{i j}-\sum_{i} P_{i} d F_{i}+\sum_{i} P_{i} \frac{\partial Q_{i}}{\partial \omega_{i}} d \omega_{i},
$$

where $\frac{\partial Q_{i}}{\partial X_{k}}$ and $\frac{\partial Q_{i}}{\partial M_{j}}$ are the partial derivatives of the output production function with respect to the $k t h$ primary input and the $j t h$ intermediate input respectively, $d M_{i j}$ is the change in intermediate input $j$ at plant $i, d F_{i}$ is the change in fixed and sunk costs, $\frac{\partial Q_{i}}{\partial \omega_{i}}$ is the partial derivative of the output function with respect to technical efficiency and $d \omega_{i}$ is the change in technical efficiency at plant $i$. $\sum_{i} P_{i} \frac{\partial Q_{i}}{\partial \omega_{i}} d \omega_{i}$ are the gains from technical efficiency changes and $-\sum_{i} P_{i} d F_{i}$ is the value of lost output arising from any incurred fixed or sunk costs. In this paper we focus on the reallocation terms which are given by the first two terms from (3).

\subsection{Linking the Gaps to Allocative Efficiency}

The reallocation terms are based on the value of the marginal products (VMP) for every input, given generically for any input $X_{k}$ at firm i as:

$$
V M P_{i k} \equiv P_{i} \frac{\partial Q_{i}}{\partial X_{k}}
$$

The reallocation terms include a VMP term and an input cost term for each plant and every primary and intermediate input:

$$
\sum_{i} \sum_{k}\left(P_{i} \frac{\partial Q_{i}}{\partial X_{k}}-W_{i k}\right) d X_{i k}+\sum_{i} \sum_{j}\left(P_{i} \frac{\partial Q_{i}}{\partial M_{j}}-P_{j}\right) d M_{i j}
$$

Using labor as an example, assuming common wages, reallocation of a unit of labor from $j$ to $i$ would lead $d L_{i}=1$ and $d L_{j}=-1$, and would thus increase the value of output by

$$
P_{i} \frac{\partial Q_{i}}{\partial L}-P_{j} \frac{\partial Q_{j}}{\partial L}
$$

while holding total labor input constant. This thought experiment motivates the following measure of forgone output, which is written in terms of labor but can be applied to any input.

Lemma 1. The average absolute gap across firms between labor's value of marginal product and wage equals the average productivity gain from adjusting labor by one unit in the optimal direction at every firm, holding all else constant. 
Proof. Define indicator variable $D_{i}$ as the unit adjustment of labor in the optimal direction for firm $i$. Then:

$$
D_{i}=\left\{\begin{array}{cl}
1 & \text { if } \quad P_{i} \frac{\partial Q_{i}}{\partial L}>W \\
-1 & \text { if } \quad P_{i} \frac{\partial Q_{i}}{\partial L}<W
\end{array}\right.
$$

The average productivity gain from adjusting labor by one unit in the optimal direction is then:

$$
\frac{1}{N} \sum_{i=1}^{N}\left(P_{i} \frac{\partial Q_{i}}{\partial L}-W\right) D_{i}=\frac{1}{N} \sum_{i=1}^{N}\left|P_{i} \frac{\partial Q_{i}}{\partial L}-W\right|
$$

Equation (6) provides a simple lower bound approximation to the potential efficiency gains to the economy from moving "one-step" in the direction of being more efficient. (6) is partial equilibrium in nature and assumes the economy is not constrained in a way that makes this labor reallocation impossible $]^{7}$

For counterfactuals we let $E 0$ and $E 1$ denote the two different states. For example, E0 might denote the state of the economy with firing costs and $E 1$ might denote the economy after all firing costs have been eliminated. We use the path of the movements of inputs, outputs, and prices between $E 0$ and $E 1$ over the interval $t \in[0,1]$ (see footnote 8 ).

We use the reallocation terms to define the change in aggregate productivity growth due to changes in allocative efficiency:

$$
\Delta A E \equiv \int_{0}^{1} \sum_{i} \sum_{k}\left(P_{i t} \frac{\partial Q_{i t}}{\partial X_{k}}-W_{i k t}\right) d X_{k t}+\int_{0}^{1} \sum_{i} \sum_{j}\left(P_{i t} \frac{\partial Q_{i t}}{\partial M_{j}}-P_{j t}\right) d M_{j t}
$$

As a simple example, consider the case of a single (labor) input firm facing an infinitely elastic labor supply curve. Suppose the firm starts from an economic environment $(E 0)$ where the firm has a positive gap between the VMP for labor and the wage as illustrated in Figure 1. This gap could be due to any type of friction, including firing costs, a tax on wages, or a markup charged by the firm. Eliminating the entire gap moves the firm to the socially optimal labor level $L^{*}$. The allocative efficiency gain would be equal to the area traced out below the VMP curve and above the wage curve.

\footnotetext{
${ }^{7}$ It also does not include any real adjustment costs (like retraining) associated with the labor movements.
} 


\section{Input Demand with Adjustment Costs}

We illustrate how market power and adjustment costs impact the allocative efficiency measure given in (7) using a simple dynamic model of input demand based on Bentolila and Bertola (1990). The production function is given as $Q\left(\omega_{t}, L_{t}\right)$ and is assumed differentiable, increasing and concave in labor $L_{t}$ (the one input), and with demand/productivity shock $\omega_{t}$. $\omega_{t}$ is stochastic so the firm is uncertain about future demand/productivity, and it is realized before the labor decision is made. Wages are exogenously set at $W_{t}$ per unit of labor and there are linear, asymmetric hiring $(\mathrm{H})$ and firing $(\mathrm{F})$ costs given as:

$$
C\left(d L_{\tau}\right)=\left(1_{\left[d L_{\tau}>0\right]} H-1_{\left[d L_{\tau}<0\right]} F\right) d L_{\tau} .
$$

We allow the firm to have some market power and assume monopoly pricing with current prices only a function of current output quantity, given as $P\left(Q_{\tau}\right)$. The firm then chooses an employment policy that maximizes the expected present value of profits over the future:

$$
V_{t} \equiv \operatorname{Max}_{L_{t}} E_{t}\left[\int_{t}^{\infty} e^{-r(\tau-t)}\left\{\left(P\left(Q_{\tau}\right) Q\left(\omega_{\tau}, L_{\tau}\right)-W_{\tau} L_{\tau}\right) d \tau-C\left(d L_{\tau}\right)\right\}\right] .
$$

Assuming the Marginal Revenue Product of labor is well-defined, we have:

$$
M R P^{l}=P \frac{\partial Q}{\partial L}\left(1+\frac{Q}{P} \frac{\partial P}{\partial Q}\right)=V M P\left(1+\frac{1}{\epsilon}\right),
$$

where $\epsilon \equiv \frac{P}{Q}\left(\frac{\partial Q}{\partial P}\right)$ is the elasticity of demand. The solution to this maximization problem depends on the current demand shock and beliefs about their future path, and sets labor according to these beliefs to satisfy:

$$
\begin{aligned}
E_{t}\left\{\int_{t}^{\infty}\left(M R P_{\tau}^{l}-W\right) e^{-(r)(\tau-t)} d \tau\right\}=-F & \text { if } d L_{t}<0 \\
-F<E_{t}\left\{\int_{t}^{\infty}\left(M R P_{\tau}^{l}-W\right) e^{-(r)(\tau-t)} d \tau\right\}<H & \text { if } d L_{t}=0 \\
E_{t}\left\{\int_{t}^{\infty}\left(M R P_{\tau}^{l}-W\right) e^{-(r)(\tau-t)} d \tau\right\}=H & \text { if } d L_{t}>0 .
\end{aligned}
$$

In this setting only when the firm faces an infinite price elasticity of demand and there are no firing costs will the value of the marginal product (VMP) be equated to the wage. Otherwise, none of the three conditions above have optimizing firms equating the value of the marginal product with marginal cost. Instead, when firing, the firm chooses labor such that the discounted expected $M R P^{l}$ given up is equal to the discounted cost of wages saved minus the firing cost. When hiring, 
the firm chooses labor to equate the discounted expected $M R P^{l}$ to the discounted cost of wages plus today's hiring cost. There is also a range of realized values for $\omega_{t}$ such that the firm does not adjust, in which case the difference between the discounted expected $M R P^{l}$ and the discounted wage falls within the range [-F,H]. Note that (9)-(11) make it clear that definitions of reallocation based on the use of cost shares are not consistent in the face of these types of adjustment costs as the first-order conditions from cost minimization no longer imply cost shares are equal to production function parameters (or markups times these parameters).

With markups but no firing costs, the optimal choice of labor in each period $t$ equates marginal revenue with marginal cost, and the firm hires or fires in every period to exactly equate the marginal revenue product with the wage. A counterfactual that eliminated firing costs but not market power would calculate how allocative efficiency as measured by (7) improves as the economy moves from a setting where firms use the decision rules from (9)-(11) to the setting where firms choose labor equating $M R P^{l}=W$ in every period.

\subsection{The Information in "Freely Adjustable" Input Gaps}

Inputs without adjustment costs will have MRP gaps that respond to some changes in economic environments but not others, making them useful as "controls" for some questions. We extend the setup to consider the case of a 2-input production function that involves labor and another "freely adjustable" input $M_{t}$, with a unit price of $P_{t}^{m}$.

Definition 1. An input $M$ is defined as "freely adjustable" if $C(d M)=0$.

The new value function in equation (8) becomes:

$$
V_{t} \equiv \operatorname{Max}_{L_{t}, M_{t}} E_{t}\left[\int_{t}^{\infty} e^{-r(\tau-t)}\left\{\left(P(Q) Q\left(L_{\tau}, M_{\tau}, \omega_{\tau}\right)-W L_{\tau}-P_{\tau}^{m} M_{\tau}\right) d \tau-C\left(d L_{\tau}\right)\right\}\right]
$$

Lemma 2 gives the decision rule for $M$.

Lemma 2. Assume $P(\cdot)$ and $Q(\cdot)$ are differentiable and $C(d M)=0$. Assume there exists a unique interior solution for $M$ conditional on $L$. Then a profit maximizing firm equates the marginal revenue product of $M$ to its marginal cost $P^{m}$ conditional on the level of chosen labor.

Proof. (12) is differentiable in $M$ so profit maximization holds if and only if conditional on $L$ the marginal revenue product of $M$ is equal to the marginal cost of $M$ for all $t$. 
Optimization for labor choice yields the same conditions as in equation (9), (10), and (11), except that the expression for marginal revenue product for labor for any $L$ will be calculated conditional on the optimal level of materials for that given $L$. The key point is conditional on the chosen labor level the marginal revenue product of any freely adjustable input will equal the contemporaneous marginal cost of that input.

The main implication for our approach is that a general change in the competitive environment that affects markups or a change in the tax on output will generally affect all input gaps, while a change in adjustment costs for one input will not affect the MRP gaps for inputs that do not have adjustment costs. Thus if VMP gaps on labor (e.g.) increase but MRP gaps on electricity and materials do not, whatever is affecting allocative efficiency of labor is unrelated to a change in markups or taxes on output.

\section{The Gap Methodology}

In this section we provide an overview of how VMP and MRP gaps can be estimated using plant-level data. Appendix $\mathrm{C}$ contains the detailed description of the approach to production function estimation and the calculation of these gaps.

We start with a Cobb-Douglas production function specification in order to estimate marginal products. We write the function as:

$$
q_{i t}=\beta_{s} l_{i t}^{s}+\beta_{u} l_{i t}^{u}+\beta_{k} k_{i t}+\beta_{m} m_{i t}+\beta_{e} e_{i t}+\beta_{v} v_{i t}+\varepsilon_{i t},
$$

where $q_{i t}$ is the $\log$ of the real output, $m_{i t}$ is $\log$ of real value of intermediate materials, $l_{i t}^{s}$ is the log of the number of skilled (white collar) employees, $l_{i t}^{u}$ is the $\log$ of the number of unskilled (blue collar) employees, $k_{i t}$ is the log of the real capital stock employed, $e_{i t}$ is log of electricity purchased (quantity), and $v_{i t}$ is log of the services used by firm $i$ in year $t$. The productivity shock is given as:

$$
\varepsilon_{i t}=\omega_{i t}+\eta_{i t}
$$

with $\omega_{i t}$ representing a transmitted component and $\eta_{i t}$ representing an iid (unexpected) productivity shock.

Given values for the production function (which we estimate in several different ways) and observed input levels, the marginal product is given for skilled labor (e.g.) by:

$$
\frac{\partial Q_{i t}}{\partial l^{s}}=\beta_{s} e^{\varepsilon_{i t}}\left(L_{i t}^{s}\right)^{\beta_{s}-1}\left(L_{i t}^{u}\right)^{\beta_{u}}\left(K_{i t}\right)^{\beta_{k}}\left(M_{i t}\right)^{\beta_{m}}\left(V_{i t}\right)^{\beta_{v}}\left(E_{i t}\right)^{\beta_{e}}=\beta_{s} \cdot \frac{Q_{i t}}{L_{i t}^{s}},
$$


where the capitalized variables are levels of the logged variables defined above. Multiplying this marginal product by the plant's output price yields the value of the marginal product $V M P_{i t}^{s}$.

The absolute value of the gap between the value of the marginal product and marginal input price for skilled and unskilled labor, $G_{i t}^{s}$ and $G_{i t}^{u}$, and for materials $G_{i t}^{m}$ and electricity $G_{i t}^{e}$ are given by:

$$
\begin{aligned}
G_{i t}^{u} & =\left|V M P_{i t}^{u}-w_{i t}^{u}\right| \\
G_{i t}^{s} & =\left|V M P_{i t}^{s}-w_{i t}^{s}\right| \\
G_{i t}^{m} & =\left|V M P_{i t}^{m}-P_{i t}^{m}\right| \\
G_{i t}^{e} & =\left|V M P_{i t}^{e}-P_{i t}^{e}\right|,
\end{aligned}
$$

where $w_{i t}^{u}$ and $w_{i t}^{s}$ denote the wage rate for unskilled (blue-collar) and skilled (white-collar) labor respectively, $P_{i t}^{m}$ is the price for materials and $P_{i t}^{e}$ is the price for electricity ${ }^{8}$ These gaps are in nominal terms, so we deflate using the consumer price index, giving:

$$
\text { Absolute real gap } \equiv R G_{i t}=\frac{\left|G_{i t}\right|}{C P I_{t}} .
$$

We also posit and estimate the parameters of a Cobb-Douglas revenue function, and using the estimated parameters, we construct estimates of the gap between MRP and input prices. A sufficient condition for a Cobb-Douglas revenue function to hold is to have an iso-elastic demand curve and a Cobb-Douglas production function. With an iso-elastic demand curve of the form $P_{i t}=A_{i t} Q_{i t}^{\frac{1}{\epsilon}}$, and a production function as in (17), the parameters of the revenue function have form $\beta_{j}^{\prime}=\beta_{j}\left(1+\frac{1}{\epsilon}\right)$ :

$$
r_{i t}=\beta_{s}^{\prime} l_{i t}^{s}+\beta_{u}^{\prime} l_{i t}^{u}+\beta_{k}^{\prime} k_{i t}+\beta_{m}^{\prime} m_{i t}+\beta_{e}^{\prime} e_{i t}+\beta_{v}^{\prime} v_{i t}+\varepsilon_{i t}^{\prime} .
$$

The procedure to estimate these parameters is very similar to that used to estimate the production function parameters, except that here we used the revenue directly (deflated by CPI to improve comparability over time).

\section{The Chilean Job Security Reforms}

Firing costs are pervasive around the world (see Figure 2, which is taken from Heckman and Pages (2004)). Theoretically it is an open question as to whether

\footnotetext{
${ }^{8}$ These gaps are linear in the value marginal product and the wage. In terms of rates of convergence, $\sqrt{n}$ consistency of the gap follows directly from $\sqrt{n}$ consistency of estimators for each of these components, which has been established for the most commonly used production function estimators.
} 
they have any impact on economic efficiency as market participants may be able to undo the distortion.9 In Chile, workers have traditionally been provided with job security through three means: advance notices for dismissal, limitations on the use of fixed-term labor contracts, and severance payments on dismissal 10 Over the 1981-1994 sample period, advance notice was unchanged at one month, and we know of no evidence of significant changes in the use of fixed-term contracts. Severance payments did change substantially on two occasions, particularly for workers that were fired for "economic" reasons. We look at these changes for evidence of an impact on economic efficiency.

There are two types of fired workers in Chile, those fired "justly" and those fired "unjustly." "Just cause" was defined in the Immobility Law of 1966, and it stated that criminal behavior and absenteeism (for example) qualified as reasons to fire someone without paying severance. Under this law, economic and financial needs were technically "just."

In 1978, the Pinochet administration started requiring firms to pay one month's wages per year of service, subject to no upper limit, for any worker dismissed for "unjustified reasons." The Labor Plan of 1980 formalized this arrangement, mandating that severance packages be part of the overall job contract negotiated between the employee and the employer. It applied to all labor contracts signed after August 1981, and it restricted the minimum severance package for "unjustified reasons" to one month's wages per year of service, subject to a maximum of five months.

The first significant enhancement in job security during the sample period occurred in June 1984, when economic and financial needs were reclassified to "unjustified." Then, in December 1990, the new democratic regime strengthened the provision. While technically reclassifying firings for economic and financial difficulties as "just," the severance package for unjust firings became the package for "just" firings, and it was further strengthened by raising the maximum severance package from five to eleven months' wages, one month per year employed. The

\footnotetext{
${ }^{9}$ Lazear (1990) shows how the distortion introduced by these provisions can potentially be completely undone by efficient contracts, where the mandated firing costs are passed on to workers who willingly accept a lower wage. In Appendix A, we look carefully at Lazear's critique in the context of Chile. Also, in a paper examining incentive effects of unemployment insurance in Chile, Hartley, Ours and Vodopivec (2010) note in a footnote that anecdotal evidence suggests that employers may reach agreement upon dismissal to pay less than the legal amount or change the cause of dismissal to avoid payment. Any empirical effects of the job security changes we find could then be interpreted as showing that regulatory stringency did actually increase in practice. Also, while there may still have been negotiated settlements below mandated rates, the regulation could have affected the extent of actual severance negotiated between the firm and the worker as it affects the threat point for the workers (and so in turn could affect firm labor choices).

${ }^{10}$ This section draws heavily from the comprehensive treatment given in Edwards and Edwards (2000).
} 
law also charged the employer a further $20 \%$ penalty when economic cause could not be established to the satisfaction of the court 11

Pagés and Montenegro (1999) construct the following index for the expected present value of the firing costs associated with hiring a laborer:

$$
C_{t}=\sum_{s=1}^{T} \beta^{s} \delta^{(s-1)} *(1-\delta) *\left(b+a_{t} S_{t+s}^{J}+\left(1-a_{t}\right) S_{t+s}^{U}\right),
$$

with $\beta$ denoting the discount factor, $\delta$ the probability of retention, $b$ the cost of advance notice, $a_{t}$ the probability that economic difficulties of the firm are considered "just," $S_{t+s}^{J}$ the payment under justified cause, and $S_{t+s}^{U}$ the payment under unjustified dismissal. $\delta^{(s-1)} *(1-\delta)$ then equals the probability of firing at year $s$ and $\left(b+a_{t} S_{t+s}^{J}+\left(1-a_{t}\right) S_{t+s}^{U}\right)$ is the expected cost associated with firing at that time 12

Figure 3 is calculated using their best estimates for a firm in Chile, and it shows that firing costs in the pre-1984 period were low, close to 0.75 months of wages, and were primarily determined by the cost of advance notice. ${ }^{13}$ Expected discounted cost increased to 2.2 months wages after the first reform in mid-1984, and then again to 3 months wages after the second reform. To put this into context for 41 OECD and Latin American countries together, Chile went from having one of the smallest levels of firing costs to being above the sample median of 2 months wages, although remaining well below the 10-14 month range of Colombia, Brazil, Peru, and Ecuador (see Figure 2) ${ }^{14}$

\footnotetext{
${ }^{11}$ The term "just" firings or dismissals is based on the phrasing of the Chilean labor law and taken from Edwards and Edwards (2000). The equivalent terminology in UK labor law and other contexts is "fair" dismissals.

${ }^{12} \mathrm{~A}$ more comprehensive approach would have indices for both the firm and the worker, $C_{i j t}$, although this calculation would require matched employer-employee data.

${ }^{13}$ They assume $\beta$ equal to $0.92, \delta$ equal to $0.88, b$ equal to $1, a_{t}$ starting at 0.8 , falling to 0 from $1985-1990$, and then increasing in 1991 to $0.9, S_{t+s}^{J}$ zero until 1990 when it increases to one month's pay for every year worked up to 11 months maximum, and $S_{t+s}^{U}$ at one month's pay for every year worked up to 5 month's maximum, for 1981-1990, and then increasing to 1.2 month's pay for every year worked up to a maximum of 11 months.

${ }^{14}$ There are a number of other political and economic changes taking place over the sample period, many of which have been analyzed elsewhere. The Labor Plan reduced payroll taxes substantially in 1981. Gruber (1997) reports that these reductions were fully passed on to wages with no effect on unemployment. The bargaining power of unions was relatively low through the 1980s under the military government, but increased under reforms introduced by the democratic regime in 1991. Using aggregate data and time series analysis, Edwards and Edwards (2000) find that reduction of payroll taxes and decentralization of bargaining increased labor market flexibility and contributed to a reduction in unemployment. Finally, there was a severe recession in 1982 related to the Latin American debt crisis and the fall in copper prices, a major Chilean export. The recovery was also quite remarkable, with wages increasing at $5 \%$ a year and unemployment falling from $17 \%$ to $5.5 \%$ in the post-recession period.
} 


\section{The Data and Variables}

\subsection{Data}

We use the annual Chilean Manufacturing Census (Encuesta Nacional Industrial Anual) conducted by the Chilean government statistical office (Instituto Nacional de Estadistica). The survey covers all manufacturing plants in Chile with more than 10 employees and has been conducted annually since 1979. There are about 5000 firms every year, with an entry rate and exit rate of about 5 percent over the panel period. We use data on the 1982-1994 period in our analysis of the gaps. Starting our analysis in 1982 eliminates the effects of the large downturn in manufacturing in 1981 (see Appendix Figure A.3).

This survey has been used in a number of previous studies ${ }^{15}$ The survey provides an industry indicator, and measures of output, inputs, wages, employment and investment. A detailed description of how the longitudinal samples were combined into a panel from 1979-1986 can be found in Liu (1991). We extended this to 1996 following broadly the procedure used by Liu. Further, we supplemented the raw data with 3-digit price series for output, machinery and inputs from other sources including IMF's IFS database, data on price indices obtained from the Chilean government statistical office, and data from Edwards and Edwards (2000) and Edwards and Edwards (1991) ${ }^{16}$

\subsection{Output, Input, Price Measures and Capital}

Plant-level real output is total revenue deflated with a 4-digit industry output deflator obtained from the Web site of the Chilean Government's statistical office. We see total person years for different types of laborers and aggregate into blue and white collar workers. Real materials and services are both aggregates at the plant-level, and each have their own 3-digit price deflator. Over 30,000 plant-year observations report zero fuel use, so we deflate fuels with its own aggregator and combine them with materials ${ }^{17}$ Services purchased include freight, insurance, rent, accounting, communications, advertising, and technical support. Real electricity input is the reported quantity of electricity purchased. Electricity price is defined as the value of electricity expenditures divided by the quantity of electricity purchased.

The real capital series is constructed using the perpetual inventory method,

\footnotetext{
${ }^{15}$ See Levinsohn and Petrin (2003) and citations therein.

${ }^{16}$ We thank Andrés Hernando for providing us with some of these deflators.

${ }^{17}$ Results are robust to dropping these observations.
} 
described in detail in Appendix D. Data on book value of capital is available for the years 1980-81 and 1992-96. We use the same methodology as Liu (1991) to construct the capital series for all firms for which we have data on book value for 1980-1991. For other firms, we build capital series backward and forward using the data on book value available for 1992-96. As in Liu, we assume a $5 \%$ depreciation rate for buildings, a $10 \%$ depreciation rate for machinery, and a $20 \%$ depreciation rate for vehicles. We use a deflator for the construction sector to deflate investments in buildings and use a deflator for machinery to deflate investments in both machinery and vehicles.

\subsection{Wage Rate Measure}

At each firm we observe the total wage bill for several types of laborers. The components of the wages are given as Wages, Bonus, Payroll Taxes, and Family Allowance Taxes. We divide the total wage bill by the number of workers to get the average wage, and we use this estimate of the average wage to approximate the marginal wage.

We examine general trends in the average real wage rates in Figure A1 (obtained by deflating the wage rate in our plant-level data using the output deflator). From separate sources we have unemployment and inflation rates across the sample period in Figure A2 and manufacturing growth in Figure A3. We find that both blue and white collar real wages dropped until the mid 1980s and then grew through the late 1980s and early 1990s. The positive increase over most of the sample period occurs along with positive manufacturing growth in every year.

While there is not an explicit category for firing costs, our understanding is these costs appear in the wage bill when they are incurred by the firm 18 For plants that fire workers, this causes the estimated average wage to be higher than the marginal wage. For blue collar workers we estimate the size of this error using an observed probability of firing of $39.2 \%$ (from Table 6 of an earlier version of our paper (Petrin and Sivadasan (2006)), an observed average fraction of workers fired given a firing spell of 17.9\% (from Table 7 of Petrin and Sivadasan (2006)), and an average tenure of 5 years for workers, which leads to a maximum payment for the first increase in firing costs. The product of these terms suggests that the estimated average wage overestimates the marginal wage by $2.8 \%$ which is small relative to the size of the gaps and the change in the gaps over time that we report in Section 8. We also note that we find approximately $62 \%$ of the estimated gaps for both blue and white collar labor are positive, and for these plants the error

\footnotetext{
${ }^{18}$ Dr. Cox-Edwards advised us on this point. Our results are robust to using only Wages and Bonus.
} 
reduces the magnitude of the estimated gap relative to its true size. We undertake further tests addressing the potential impact of wage mis-measurement in Section 8 but find no evidence that this mis-measurement could explain either the size of the gaps or their change over time.

\section{Estimation}

There are some important issues that a researcher will confront in practice: estimation of production function parameters and simultaneity, functional form for production, observing revenues versus quantities, measurement error in estimated productivity, and estimation of input prices. We discuss each in turn.

A wide variety of production function estimators are available to researchers using plant-level (or industry level) panel data. In the baseline analysis, we employ the approach proposed by Wooldridge (2009) that synthesizes ideas to address the simultaneity problem from Levinsohn-Petrin (2003) and Olley and Pakes (1996), while also addressing the critique of these approaches by Ackerberg, Caves and Fraser (2006). We use the proxy variable (materials) proposed by LP to investment proxy proposed by OP because of the well-known lumpiness of investment in plantlevel data. We estimate the production function separately by 3-digit industry to allow these parameters to vary by industry. Also, given that the job security reforms introduce adjustment costs to labor inputs, we treat blue and white collar labor as state variables (in addition to capital) in the estimation. Appendix $\mathrm{C}$ has more details on the estimation approach as well as a discussion of estimates and overidentification tests 19

As in many plant-level data sets we observe plant-level revenues and not prices and quantities separately. Two approaches have been proposed to deal with production function estimation in this case. One approach deflates plant-level revenues by an industry price-deflator and then uses deflated revenues as the dependent variable in the production function regressions. Production function estimates are consistent if inputs are not correlated with the deviation of the plant-level price from the industry price index. An alternative is to assume that demand takes a particular functional form and use that functional form to back out a price control, as in Klette and Griliches (1996). While both approaches have their weaknesses, we follow the predominant approach in the literature and use the former.

When constructing an estimate of the value of the marginal product in the

\footnotetext{
${ }^{19}$ Programs available in a Programming Appendix at: http://webuser.bus.umich.edu/jagadees/other/chile_code.htm
} 
face of this price measurement error, we use the entire error from the production function estimates. Since this includes the ratio of the plant-level price to the industry price, we then multiply this estimate by the industry price deflator so only the plant-level price times the marginal product remains. For example, with the Cobb-Douglas production specification considered in Section 4, for skilled labor when we use the entire error in the estimation of the marginal product, we get

$$
\beta_{s}\left(\frac{P_{i t} Q_{i t}}{P_{h t}}\right)\left(\frac{1}{L_{i t}^{s}}\right)
$$

with $P_{h t}$ the industry price deflator. We then multiply this by $P_{h t}$ to recover the value of the marginal product.

Another issue relates to whether the estimated error from the production function is all productivity, or whether it also contains measurement error in quantity. When the estimate of the marginal product is undertaken, the "error" that should be used is the part of the error that is productivity. In our baseline estimates, we condition on the full error term, but we also check robustness to estimating and conditioning on the predictable (transmitted) component of the error term.

Finally, input prices are sometimes reported in plant-level data, but more often one observes total expenditures on the inputs and total units of the input, so the average input price will often be used in place of the marginal price.

\section{The Gap Results for Chile, 1982-1994}

\subsection{Baseline Results}

Over the entire sample period, we observe 43,675 gaps for blue collar, with 9,558 observations in the three-year period prior to the first reform $(1982,1983$ and 1984), 18,852 observations in the period between the two reforms (from 1985-1990), and 15,265 observations in the four year period after the second reform (from 19911994). Before conditioning on plant-specific differences and other observed control variables, we analyze the unconditional means and medians of the gap distribution.

The average (median) unconditional gaps for blue collar labor in real terms across the three periods are 79 (33), 107 (35), and 112 (41) thousand pesos. ${ }^{20}$ The average (median) unconditional gaps for white collar labor across periods are 124 (69), 155 (83), and 173 (95) thousand pesos. These compare to average wages in our data of 77 thousand pesos a year for blue collar workers and 158 thousand pesos a year for white collar workers. Thus the average gaps are close to or more

\footnotetext{
${ }^{20}$ All results are report in real 1979 Chilean pesos.
} 
than a year's wage for both types of workers. The gaps are also growing over time for both types of laborers.

In Table 1, we summarize the changes in the gaps across the three periods for blue collar labor, white collar labor, materials, and electricity. In each column the absolute value of the gap for the input is the dependent variable. All regressions include two period-indicators for the different degrees of job security, one for 19851990, and one for 1991-1994. Columns 2, 4, 6, and 8 also include the industry output growth rate as a control for industry level demand shocks. We include plant fixed effects which allow for base-period plant-specific gaps, so the magnitudes of the period dummies are identified by within-plant variation in the mean gap over time.

From Lemma 1 we know that the average absolute gap for an input in any period is an approximate measure of the potential gain in productivity from a unit adjustment of that input in the optimal direction. The results in Table 1 suggest that, in the base period, the potential gain from a unit adjustment in blue collar labor was 84 thousand pesos per year, and for white collar labor it was 139 thousand pesos per year. In the second period, potential gains from a unit adjustment for both the blue collar and the white collar gaps increase significantly, by 23 thousand pesos and 18 thousand pesos respectively. In the third period, the blue collar gap increases slightly (by about 2 thousand pesos), while the the white gap increases further, by almost 6 thousand pesos relative to the second period. The longer tenure of white collar workers is consistent with a bigger change in response to the second increase in job security ${ }^{21}$ For the base period, a one-step move of blue-collar labor in the "right" direction leads to almost a $0.5 \%$ increase in value added.

Using the same regressions, Figure 4 more closely examines the statistical significance of the year-to-year indicator variables relative to 1984 for both the absolute value of the gap for blue and white collar labor. The two horizontal lines indicate the average level of the gap in 1984 for blue and white collar labor. Confidence intervals for yearly indicator variables that do not contain the line are significantly different from the 1984 level. All nine of the blue collar as well as white-collar year dummies after 1985 are significantly different from 1984.

The timing of the results are consistent with the timing of the job security changes. The labor gaps are fairly level for white collar employees in the prechange period until 1985, when they increase in 1986-87 after the first application

\footnotetext{
${ }^{21}$ Results are robust to $\log$ specifications, and the results are similar to what we report for the levels specifications. When working in levels, we replace the biggest $2.5 \%$ of the gaps with the value of the 97.5 th percentile, and similarly for the smallest $2.5 \%$ of the gaps (i.e. we winsorize the observations by $2.5 \%$ on both tails).
} 
of job security. For blue collar, there are some increases in the gap in 1984 and 1985, but a bigger increase in 1986-87. The gaps decline somewhat by 1990 for both blue and white collar, but increase again in 1991, at the time of the second increase in job security (though this increase is smaller than the jump in 1986).

By Lemma 2 we know if changes in markups or output taxes (e.g.) are the cause for the increased gap between labor VMP and wages that we see in in Table 1 then we should see this change drive a gap between MRP and input prices for all inputs. In Table 2 we report estimates of the marginal revenue product gaps for materials and electricity. Examining the VMP results in columns 5-8 of Table 1 for materials and electricity as well as the MRP results in Table 2 we find that in contrast to the patterns for labor inputs, there is no increase in VMP or MRP gap for either materials or electricity across the two periods 1985-1990 and 1991 on. Thus, whatever the reason for the increase in gaps for labor input the results suggest it is not a "friction" that affects all inputs.

We compare the year-to-year timing of the changes in gaps across inputs. Figure 5 plots the coefficients on the year dummy variables that come from regressing the absolute value of the gap for the input on industry output growth rate (as a control for industry level demand shocks) as well as plant specific fixed effects which allow for base-year (1981) plant-specific gaps. Gaps for all inputs are normalized to 100 in 1984 for this comparison. The graph tells a story similar to the above tables, with labor input gaps increasing and materials and electricity gaps decreasing slightly.

\subsection{Robustness Checks}

In this section we examine robustness to: (i) alternative production functions; (ii) an alternative definition of the productivity residual; (iii) measurement error in wages; (iv) differences in excess worker turnover; (v) differences in industry unionization rates; (vi) use of an alternative deflator for nominal gaps; and (vii) exclusion of entrants and exiters. Our main findings are robust to all of these checks. We also show gaps are correlated with probability of exit.

\subsubsection{Alternative Production Function Specifications}

We use the same specification as in equation (17) but estimate it using plant-level fixed effects that vary by the three time periods. This estimator is consistent if $\omega_{i t}=\omega_{i p}$ where $p$ stands for one of the three time periods (period 1 is 1982-1984, period 2 is 1985 to 1990, and period 3 is 1991-1994). The results, presented in 
columns 1 to 4 of Table 3, are similar to those in the baseline Table 1 . We find slightly larger increases for blue- and white-collar gaps in both periods. Contrary to the base case, we find a slight increase in the blue-collar gap, and a slight decline in the white-collar gap, from period 2 to 3 . As in the base case, we find declines in the gap for both materials and electricity.

One drawback of the Cobb-Douglas specification in equation (17) is that the elasticities of output with respect to individual inputs are restricted to be constant and the elasticity of substitution between inputs is restricted to be one. As an alternative, we consider the following second order translog specification:

$$
q_{i t}=\sum_{j} \beta_{j} X_{i t}^{j}+\beta_{j j} X_{i t}^{{ }^{2}}+\sum_{j \neq k} \sum_{k} \beta_{j k} X_{i t}^{j} \cdot X_{i t}^{k}+\varepsilon_{i t}
$$

where $i$ indexes plants, $t$ indexes years, $j$ and $k$ index the different inputs. We estimate the translog production function using the same fixed effects. The gap results using the translog production function are presented in columns 5 to 8 of Table 3. Again we find broadly the same patterns as in the basecase in Table 1 both for the labor inputs and the control inputs.

\subsubsection{Using Transmitted Component of Productivity}

In this section, we check robustness of the results to conditioning on only the transmitted component of productivity. As discussed in Section 4, if $\eta_{i t}$ arises essentially from measurement error in output then this term should be eliminated from the productivity residual when estimating the marginal product. In order to eliminate $\eta_{i t}$, we form an estimator for $\omega_{i t}$ in the following way. First, we run the first stage regression of output on variable inputs and a polynomial in capital and the proxy variable and obtain the predicted output level $\left(\hat{q_{i t}}\right)$ from this regression. This yields the output net of the unpredicted part of the productivity term $\eta_{i t}$. Then we subtract the contribution of the inputs using the coefficient estimates obtained earlier, so that we get $\hat{\omega_{i t}}=\hat{q_{i t}}-\left(\hat{\beta_{s}} l_{i t}^{s}+\hat{\beta_{u}} l_{i t}^{u}+\hat{\beta_{k}} k_{i t}+\hat{\beta_{m}} m_{i t}+\hat{\beta}_{e} e_{i t}+\hat{\beta_{v}} v_{i t}\right)$. The results are presented in Table 4 . These are qualitatively similar to that in baseline case in Table 1.

\subsubsection{Measurement Error in Wages}

In Section 6.3 we showed that a simple estimate of the amount of error introduced into the gap estimate and its change by the inability to separate severance pay from the wage bill is small. Here we further explore the issue by noting that the

measurement error does not arise for plants that do not fire workers. Thus, the 
average industry wage rate in plants that increased employment may provide an unbiased estimate for the going market wage rate. Specifically, for all plants in industry $j$ in period $t$, we take as a proxy for the going marginal blue collar wage rate:

$$
w_{j t}=\frac{\sum\left(W A G E B I L L_{i j t}-W A G E B I L L_{i j t-1}\right) \cdot I_{\Delta L_{i j t>10 \%, \Delta W>0}}}{\sum\left(L_{i j t}-L_{i j t-1}\right) \cdot I_{\Delta L_{i j t}>10 \%, \Delta W>0}}
$$

where $I_{\Delta L_{i j t}>10 \%, \Delta W>0}$ is an indicator dummy $=1$ for plant $i$ in sector $j$ in period $t$ if it experienced an increase in blue collar employment greater than $10 \%$ and experienced an increase in the blue collar wage bill. We define the proxy for marginal wage for white collar wages similarly. We rerun our gap estimates using these industry-level wage rates and the results are presented in Table 5 (columns 1 to 4 ). We find that the baseline results are quite robust to using this alternative measure of wages.

We also look at how the gaps change for just the plants that have positive gaps. As we noted in Section 6.3, the upward bias in measured wage for firms that fire workers leads to a downward bias on measured absolute gaps for observations with positive gaps. The results from examining this subsample are presented in Table 5 (columns 5 to 8 ). We continue to find significant increases in both blue and white collar gaps in the periods after the passage of the laws relative to the period before the laws.

\subsubsection{Conditioning on Excess Worker Turnover}

In industries that have relatively high voluntary worker turnover managers should have more flexibility to adjust employment levels down without firing workers. If the increases in the gap for blue and white collar labor are indeed driven by the changes in firing costs we expect these increases to be lower in industries that have higher voluntary worker turnover rates. Combining this with the expectation that mandated severance payments should have no effect on the gaps for the freely adjustable inputs, we get a test in the spirit of difference-in-difference-indifferences.

We proxy for the extent of Chilean industry-level voluntary turnover using U.S. excess worker turnover (defined as worker turnover less job turnover). Data on job and worker turnover are obtained form the quarterly workforce indicator (QWI) database, which is based on data from the LEHD ${ }^{22}$ We collected data

\footnotetext{
${ }^{22}$ The QWI database by SIC code is available at http://lehd.did.census.gov/led/datatools/qwiappssic.html. Detailed documentation on the construction of the QWI is presented in Abowd et al (2005). Because the LEHD does not track the reason for separations, data on voluntary separations (or quits) is not available in the QWI.
} 
by 3-digit SIC code for 1995, which we cross-linked with the ISIC based industry classification in the Chilean data using a concordance between the SIC 3-digit code and the ISIC 3-digit code.

We then split out sample into two groups. One group contains estimated gaps from plants in industries with excess turnover above the median and the second group contains the plants in industries below the median. In Table 6, we find the increases in gaps for blue-collar and white-collar worker (in columns 1 and 2) are bigger in magnitude for plants below the median. This pattern holds for both period 2 and period 3 and for both blue and white collar workers. The results for materials and electricity (columns 3 and 4 ) do not show systematically larger increases in gaps for plants below the median in either period 2 or period 3 . The evidence is thus consistent with at least some of the increase in the labor gaps being attributable to the increase in firing costs ${ }^{23}$

\subsubsection{A Sample-split Test Based on Unionization Rate}

As discussed in Edwards and Edwards (E\&E) (1999), new laws on unions' rights and collective bargaining went into effect in 1991. According to E\&E, the law change was intended "to move collective bargaining away from the centralized European model to the decentralized United States model." Different indices related to the collective bargaining process indicate that "labor unions became less important, and the process itself became more decentralized." In particular, a bargaining index constructed by E\&E suggests more decentralization after 1991. E\&E also examine labor unrest index and find a decline in the post-1992 period (after a spike around 1991-1992).

We expect the main effect of changes in the bargaining and quality of labor relations to be on the level of wages and labor costs, which is captured in our wage measure and not necessarily in the gaps. Nevertheless, as a robustness check we examine the changes in gaps separately for industries above and below the median unionization rate. We expect any bias from changes in bargaining power to disproportionately affect those industries with higher unionization rates.

We use data from the Social Protection Survey (Encuesta Proteccin Social)

The only publicly available data on we were able to locate was average for the period 1958-1979 by 2-digit industry from Ragan (1984), based on a discontinued BLS labor turnover survey (Utter, 1982). We found very high correlation between the excess turnover from the QWI and the quit rate in Ragan (1984) - the correlation was 0.81 , and significant at 1\%. (Starting in 2000, the US Bureau of Labor Statistics has been conducting the Job Openings and Labor Turnover Survey (JOLTS) that does collect information on type of separation. However, per the BLS, the sample size (16,000 units) is too small publishing data at a disaggregated 3-digit (or even 2-digit) SIC level.)

${ }^{23}$ Results were qualitatively robust to using the OLS fixed effects production function (available on request). 
which is for the years 2002-2009 24 The data for 2009 includes information on the labor histories for each respondent (going back to 2006). For each historical employment spell, the respondents industry of employment (4 digit ISIC) as well as union membership status is tracked. We define a unionization rate at the 3 digit industry level as the fraction of observations for the industry where the respondent reported belonging to the union 25 The results from examining samples split based on industry unionization rates are presented in Appendix Table A.4. We find that the increase in average absolute gaps for white and blue collar labor is as big, if not bigger, in industries below the median in terms of unionization rates. Again, there is no systematic pattern of increase in either sets of industries for the control inputs. 26

\subsubsection{Robustness to using an Alternative Deflator}

In the baseline analysis, we deflate the nominal gaps with the CPI to denote all gaps in 1979 pesos. The results from using the GDP deflator are presented in Appendix Table A.5 and are very similar to using the CPI deflator.

\subsubsection{Robustness to Entry and Exit}

Because we use plant-level fixed effects in the gaps regressions, the changes in gaps for the period 2 (1985-1990) and period 3 (1991-1994) are identified off plants that exist in at least 2 of the three time periods. We investigate whether changes in composition from new entrants in period 2 that carry over to period 3 or plants that survived from period 1 to 2 but exit in period 2 impact the results. In columns 1 to 4 of Appendix Table A.6, we restrict observations to plants that existed in at least 2 out of the three years 1982-1984), all 6 years of period 2 (1985-1990) and at least 2 of the 4 years of period 3 (1991-1994). In columns 5 to 8 , we use a less restrictive condition, retaining plants that existed in at least 2 years in each of the three time periods. The results are qualitatively very similar to the baseline results.

The checks in columns 1-4 also address a concern arising from limitations in the measurement of capital stock. As discussed in Appendix D, for plants that

\footnotetext{
${ }^{24}$ Landerretche, Lillo, and Puentes (2011) use this survey to study the effect of unions on wages. The data was generously provided to us by the Microdata Center at the University of Chile. In particular, we thank Esteban Puentes for facilitating access to the data and helping us with data related questions.

${ }^{25}$ Spells corresponding to inactivity or cessation from the labor market are excluded. Also, 3-digit industries for which we had fewer than 20 observations was excluded; this only lead to the exclusion of 4 smaller 3 -digit industries that constituted about $5 \%$ of the data we used in the baseline analysis.

${ }^{26}$ Results were qualitatively robust to using the OLS fixed effects production function (available on request).
} 
exit the sample for short durations we assume that the investment is zero in the missing years. This may lead to systematic mis-measurement of capital series (as any mis-measurement in investment gets propagated when using the perpetual inventory method to build the capital series). Because the mis-measurement due to missing data is not a concern for the sample in columns 1-4, the robustness of the baseline results in this sample is reassuring.

\subsubsection{Correlation between Gap and Exit Hazard/Propensity}

We explore whether plants with larger absolute gaps are more likely to exit using an exponential hazard model as well as a linear probability model. We control for size and age in both setups. Industry-year fixed effects are included in the linear model and industry and year dummies are controlled for separately in the hazard models (where including a large number of fixed effects is computationally cumbersome). The results are presented in Appendix Table A.7. We find that larger blue collar gaps are indeed significantly associated with higher exit hazard and propensity (column 1 and column 3). We find that the result holds for both positive and negative blue collar gaps separately (columns 2 and 4). Similarly, we find in columns 5 and 6 that the white collar gaps are associated with higher exit hazard, but this effect is not statistically significant except in the case of negative gaps. The effects are significant in the linear exit propensity models (where all effects are statistically significant).

\section{Conclusions and Extensions}

In this paper we propose a new methodology to measure the impact of any type of friction that reduces allocative efficiency by driving a wedge or "gap" between the value of the marginal product (VMP) of an input and its marginal cost. We show that the mean absolute gap between the value of marginal product and input price is related to allocative inefficiency in terms of its impact on aggregate productivity growth. In particular, the mean absolute gap corresponds to the mean change in aggregate productivity from adjusting the input by one unit in the optimal direction.

Our approach is simple, transparent, and can readily be carried out in standard programming packages on aggregate data or the large micro-datasets that are increasingly available for different countries and time periods. We discuss a number of estimation and measurement issues relating to the application of the method and propose a number of robustness checks to address potential concerns. In the 
context of assessing the impact of policy changes that affect adjustment costs for particular inputs, we show how gaps for other inputs can serve as controls to rule out changes from frictions such as output taxes and subsidies or non-optimal managerial behavior that would be expected to affect the gaps for all inputs.

We use the VMP-input price gap to examine overall allocative inefficiency in Chile. We also focus on the effects of two mandated increases in the costs of dismissing employees. We find sizable gaps for blue and white collar labor even prior to the increases in firing costs. We also find statistically significant changes in the within-firm absolute gap between the marginal product of labor and the wage for both white and blue collar workers following increases in job security. We find little impact on gaps for materials and electricity arising from the firing costs. The interpretation of the results are subject to the caveat that the data available for Chile are imperfect, as discussed and addressed to the extent possible in Section 8.2 of the paper.

We see the main contribution of the paper as proposing a simple and novel methodology to estimate allocative inefficiency. This gap analysis is applicable to many economic questions beyond the effects of firing costs. Our plant-level gap statistic can be used to look for effects of any policy that introduces additional terms to the plant's first order condition. In terms of the allocative efficiency implications, if the gap is increasing, then willingness to pay and cost of production diverge from one another.

\section{References}

[1] Abowd, John M., Bryce E. Stephens, Lars Vilhuber, Fredrik Andersson, Kevin Mckinney, Marc Roemer, and Simon Woodcock. "The LEHD Infrastructure Files and the Creation of the Quarterly Workforce Indicators." technical paper No. TP-2006-01, UC Census Burea, LEHD Program (2005).

[2] Ackerberg, D., Caves, K., and G. Fraser, "Structural Estimation of Production Functions." UCLA Working Paper, (2006).

[3] Aghion, P. and P. Howitt, " A Model of Growth Through Creative Destruction." Econometrica, 60, (1992) 323-351.

[4] Alvarez, F., and M. Veracierto. "Severance Payments in an Economy with Frictions." Journal of Monetary Economics 47, no. 3 (2001): 477-98. 
[5] Bailey, M., Hulten, C., and Campbell, D. "Productivity dynamics in manufacturing plants." In Brookings Papers on Economic Activity: Microeconomics, Vol. 4, pp. 187-267. Brookings Institute, (1992).

[6] Basu, S., and Fernald, J. "Aggregate productivity and aggregate technology." European Economic Review, 46. (2002) 963-991.

[7] Bentolila S. and Bertola, G. "Firing Costs and Labour Demand: How Bad is Eurosclerosis?" Review of Economic Studies. 57. (1990) 381-402.

[8] Bertola, G. "Job Security, Employment and Wages." European Economic Review. 34 (1990): 851-86.

[9] Bond, S. and J. Van Reenen, "Microeconometric models of investment and employment." in J.J. Heckman and E.E. Leamer (eds.) Handbook of Econometrics, Volume 6 (2007).

[10] Burgess, S., Lane, J. and Stevens, D. "Job flows, worker flows and churning, Journal of Labor Economics, Vol. 18, (2000) 473-502.

[11] Caballero, R, and E. Engel. "Microeconomic Adjustment Hazards and Aggregate Dynamics." Quarterly Journal of Economics, 108, no. 2 (1993): 359-383.

[12] Caballero, R, and E. Engel. "Explaining Investment Dynamics in U.S. Manufacturing: A Generalized (S,s) Approach." Econometrica, 67, No. 4 (1999): 783-826.

[13] Caballero, R, and E. Hammour. "On the Timing and Efficiency of Creative Destruction" Quarterly Journal of Economics, 111, No. 3 (1996): 805-826.

[14] Edwards, S., and A. Edwards, Monetarism and Liberalization: The Chilean Experiment, Second Edition with a New Afterward (in collaboration with A. Cox-Edwards), Chicago: University of Chicago Press, 1991.

[15] Edwards, S., and A.C. Edwards, "Economic Reforms and Labor Markets: Policy Issues and Lessons from Chile." NBER Working Paper No. 7646, 2000.

[16] Foster, L., Haltiwanger, J., and Krizan, C. . "New Developments in Productivity Analysis," chap. Aggregate Productivity Growth: Lessons from Microeconomic Evidence, pp. 303-372. University of Chicago Press (2001). 
[17] Gruber, J. "The Incidence of Payroll Taxation: Evidence from Chile." Journal Of Labor Economics 15, no. 3 (1997): S72-S101.

[18] Hartley, Gonzalo Reyes, Jan C. van Ours, and Milan Vodopivec. "Incentive Effects of Unemployment Insurance Savings Accounts: Evidence from Chile." Discussion Paper No 4681, IZA (2010).

[19] Heckman, J.J., and C. Pages. "Law and Employment: Lessons from Latin America and the Caribbean," Introduction in Law and Employment: Lessons from Latin America and the Caribbean University of Chicago Press, (2004).

[20] Hopenhayn, H., and R. Rogerson. "Job Turnover and Policy Evaluation a General Equilibrium-Analysis." Journal Of Political Economy 101, no. 5 (1993): 915-38.

[21] Hsieh, C. T., and P. J. Klenow. "Misallocation and Manufacturing TFP in China and India." Quarterly Journal of Economics 124, no. 4 (2009): 1403-48.

[22] Klette, T. J., and Z.Griliches, "The Inconsistency of Common Scale Estimators When Output Prices are Unobserved and Endogenous," Journal of Applied Econometrics, 11, (1996): 343-361.

[23] Landerretche, Oscar, Nicolá s Lillo, and Esteban Puentes. "The Union Effect on Wages: A Two-stage Approach Using Panel Data." Working Paper, Universidad de Chile, Santiago (2011).

[24] Lazear, E. P. "Job Security Provisions and Employment." Quarterly Journal Of Economics 105, no. 3 (1990): 699-726.

[25] Levinsohn, J., and A. Petrin. "Estimating Production Functions Using Inputs to Control for Unobservables." Review Of Economic Studies 70, no. 2 (2003): 317-41.

[26] Liu, L., "Entry-exit and productivity change: An empirical analysis of efficiency frontiers." Ph.D. dissertation (University of Michigan, Ann Arbor, MI) (1991).

[27] Olley, G. S., and A. Pakes. "The Dynamics of Productivity in the Telecommunications Equipment Industry." Econometrica 64, no. 6 (1996): 1263-97. 
[28] Pagés, C., and Montenegro. C. "Job Security and the Age-Composition of Employment: Evidence from Chile." Working Paper 398. Washington, D.C., United States: Inter-American Development Bank (1999).

[29] Petrin, A., and J. Levinsohn. "Measuring Aggregate Productivity Growth Using Plant-level Data," University of Minnesota Working Paper (2011).

[30] Petrin, A., Levinsohn, J., and B. Poi, "Production Function Estimation in Stata Using Inputs to Control for Unobservables," Stata Journal , 2004.

[31] Petrin, A. and J. Sivadasan. "Job Security Does Affect Economic Efficiency: Theory, A New Statistic, and Evidence from Chile," NBER Working Paper No. 12757 (December 2006).

[32] Ragan, James F. "Investigating the Decline in Manufacturing Quit Rates." The Journal of Human Resources Vol 19, No 1 (Winter 1984) 53-71.

[33] Rajan, R. G., and L. Zingales. "Financial Dependence and Growth." American Economic Review 88, no. 3 (1998): 559-86.

[34] Risager, O., and J. R. Sorensen. "On the Effects of Firing Costs When Investment Is Endogenous: An Extension of a Model by Bertola." European Economic Review 41, no. 7 (1997): 1343-53.

[35] Utter, Carol. " Labor Turnover in Manufacturing: the Survey in Retrospect." Monthly Labor Review (June 1982) 15-17.

[36] Wooldridge, J. M. "On Estimating Firm-Level Production Functions Using Proxy Variables to Control for Unobservables." Economics Letters 104, no. 3 (2009): 112-14. 


\section{Appendix A: Undoing the Distortion with Contracts}

If there is efficient bargaining between the worker and the employer a contract can be written specifying a side payment from the worker to the firm that fully offsets the firing cost (Lazear (1990)). Consider one such scheme for the 2-period case with no discounting and a constant wage ${ }^{27}$ The firm pays $w$ in period 1 to the worker, with the worker agreeing to set aside $c$ until period 2. In period 2, if $\theta_{2}<\theta_{1}$, each worker who is fired receives $c$. All retained workers receive $w+c$. If $\theta_{2} \geq \theta_{1}$, then retained workers receive $w+c$ and new hires get $w$.

This contract allows the firm to pay firing costs out of the worker's salary from the previous period. The optimal choices of labor and the hiring and firing rule remain unchanged from the non-distorted setting. The marginal cost faced by the firm is $w$ in each period regardless of whether the firm hires or fires. Workers' labor force participation choice is also unaffected, as they receive the same wage as in the regime with zero firing costs. Since no distortions are introduced into the market, efficiency means welfare continues to be maximized.

Lazear (1990) argues that the inefficiency may be difficult to undo using side payments for many practical reasons. In particular, workers must be willing to make the side payments to the employer or into an insurance fund; apprehension on the part of workers regarding the future severance payment could prevent the distortion's undoing ${ }^{28}$ Also, from an efficiency standpoint, firing probabilities are dependent on worker characteristics and firm layoff experience, so any unemployment insurance plan that does not condition on these factors is not going to maximize welfare.

For an estimate of the per period reduction in wages required to offset the two job security changes introduced in Chile, we consider two "insurance" plans. Under the first, expected firing costs are recovered through premium payments over the lifetime of the worker in the firm. Under the second, the firm insures against the possibility of firing workers period by period.

\section{A.1 Plan 1: Insuring over the Worker's Lifetime}

Under this plan, wage premia are collected over the worker's tenure with the firm to offset the expected firing costs. The fair premia for worker $j$ is given by $\alpha_{j}$, a fraction of annual wages, and is calculated by setting the expected present value of the dismissal costs equal to the present value of the premia collected:

$$
\sum_{s=1}^{T} \beta^{s} \delta_{j}^{s}\left(1-\delta_{j}\right)\left(y_{j, t+s}\right)=\sum_{s=0}^{T-1} \beta^{s} \delta_{j}^{s} \alpha_{j} W_{j},
$$

where $\beta$ is the discount factor, $\delta_{j}$ is the probability of worker $j$ being retained, $y_{j, t+s}$ is the severance cost in annual wages of firing worker $j$ at end of $s$ years, and $T$ is the maximum tenure. Assuming that all workers in a firm have identical wages and dismissal probabilities, we can calculate the drop in wage levels (ie the premium payments) required to offset any increase in dismissal costs. We estimate how large the fall must be to offset the first job security reforms introduced in Chile, assuming the interest rate (for discounting) is $5 \%$ and the maximum tenure is 20 years.

\footnotetext{
${ }^{27}$ This contract can be written for the infinite-horizon case, with the firm and the worker agreeing to a similar arrangement period-by-period.

${ }^{28}$ Even if the workers are willing to make side payments, other problems exist, including potential moral hazard problems like workers attempting to obtain the severance package early, or agency problems like managers colluding with workers to extract excess severance payouts in the face of full insurance.
} 


\begin{tabular}{|c|c|c|}
\hline Current tenure & Dismissal rate & Implied wage change in year 1 \\
\hline all new & $10 \%$ & $\mathbf{- 3 . 0 9} \%$ \\
all new & $15 \%$ & $\mathbf{- 4 . 2 5} \%$ \\
all new & $20 \%$ & $\mathbf{- 5 . 1 9} \%$ \\
all > 5 years & $10 \%$ & $\mathbf{- 4 . 1 7} \%$ \\
all > 5 years & $15 \%$ & $\mathbf{- 6 . 2 5} \%$ \\
all > 5 years & $20 \%$ & $\mathbf{- 8 . 3 3} \%$ \\
\hline
\end{tabular}

\section{A.2 Plan 2: Insuring Period by Period over the Pool of Workers}

In this approach, the firm's expected firing cost for each period is insured by collecting a premium from all the workers of the firm. Assuming the same fraction of wages is collected from each worker, the fair premium in this case is obtained by setting:

$$
\sum_{j=1}^{N_{j}} \delta_{j} y_{j}=\alpha \sum_{j=1}^{N_{j}} W_{j},
$$

where $\delta_{j}$ is the probability of worker $j$ being retained, $y_{j t}$ is the severance cost in annual wages of firing worker $j$ and $N_{j}$ is the number of workers in firm $j$. Assuming that the workers in the firms are identical, we obtain the required drop in wage levels to pay for the insurance premia that offsets the first increase as:

\begin{tabular}{|c|c|c|}
\hline Current tenure & Dismissal rate & Implied wage change in year 1 \\
\hline all new & $10 \%$ & $\mathbf{- 0 . 8 3} \%$ \\
all new & $15 \%$ & $\mathbf{- 1 . 2 5} \%$ \\
all new & $20 \%$ & $\mathbf{- 1 . 6 7 \%}$ \\
all > 5 years & $10 \%$ & $\mathbf{- 4 . 1 7} \%$ \\
all > 5 years & $15 \%$ & $\mathbf{- 6 . 2 5} \%$ \\
all > 5 years & $20 \%$ & $\mathbf{- 8 . 3 3} \%$ \\
\hline
\end{tabular}

If workers are identical and $y_{j, t+s}$ is constant over all $j$ (as in the case where the tenure of all workers exceeds 5 years), the premium payments are the same for both plans and given by $(1-\delta) y$

Since we expect the current average tenure of typical firm to be between the extremes considered in the tables above, we guess that the fall in wages required to neutralize the Chilean 1984 dismissal cost might lie in the range of $3 \%$ to $6 \%$. The second job security change increases the maximum dismissal cost from 5 months to 11 months, implying an additional drop that is similar in magnitude.

\section{A.3 Empirical Evidence on Wages}

To try to separate out the effect of job security changes on wages, we regressed the estimated plant-level average real wage on period controls for the job security changes. The other controls include firm fixed effects, firm output growth rate, industry output and industry growth rate, and the unemployment rate. Unfortunately, we do not observe worker-specific covariates.

We report the estimates in Appendix Table A.1. In all the specifications, there is a major decline in wages in period $2(1985-1990)$. The extent of the decline, between $36 \%$ and $53 \%$, is much larger than that required under our offset plans. In period 3, wages recover somewhat. Overall, there is no clear evidence that the job security changes were offset through lower wage rates. 


\section{Appendix B: Wage Rate Variation within Blue/White Collar Categories}

In our data there is variation in the wage rates across plants for both blue and white collar labor. If these differences exist because of market imperfections, then these wages are the marginal wages and there is no measurement problem. If they reflect differences in labor quality, then labor quantity is measured with error as it is not properly adjusted for unobserved labor quality.

The potential bias in the measured gap may not be high, as measurement error on the wage side is offset by a higher measured marginal product per unit labor, as the firms with higher quality workers have higher estimated productivity levels. For example, consider firm A that employs half the workers as firm B, but of twice the quality level as firm B, and pays them twice the wage. Ideally, we may wish to use a quality adjusted measure for labor and wages for all firms. In the absence of this data, the measured wage for A will of course be higher than for B. But note that the measured productivity level will be higher for A, which will increase the marginal product for A. Also, as noted above the fact that marginal revenue is declining in inputs means that the lower labor level at A will lead to a higher estimated marginal revenue product for A. Thus A has both a higher measured marginal revenue product, and higher measured wages, so the biases work to counteract each other. If the amount of measurement error in labor quality does not change in response to increases in firing costs then this error in the marginal revenue product is unlikely to vary in a way that would lead to finding larger gaps in periods of higher firing costs.

\section{Appendix C: Wooldridge (2009) Production Function and Gap Estimation}

\section{C.1 Wooldridge-LP production Function Estimation}

This appendix section explains the approach used to estimate the production function parameters used in our baseline analysis, which is based on Wooldridge (2009). As discussed in section 4. we posit a Cobb-Douglas production function:

$$
q_{i t}=\beta_{s} l_{i t}^{s}+\beta_{u} l_{i t}^{u}+\beta_{k} k_{i t}+\beta_{m} m_{i t}+\beta_{e} e_{i t}+\beta_{v} v_{i t}+\varepsilon_{i t},
$$

where $q_{i t}$ is the $\log$ of the real output, $m_{i t}$ is $\log$ of real value of intermediate materials, $l_{i t}^{s}$ is the log of the number of skilled (white collar) employees, $l_{i t}^{u}$ is the log of the number of unskilled (blue collar) employees, $k_{i t}$ is the log of the real capital stock employed, $e_{i t}$ is log of electricity purchased (quantity), and $v_{i t}$ is $\log$ of the services used by firm $i$ in year $t$. The error, $\varepsilon_{i t}$, is assumed equal to:

$$
\varepsilon_{i t}=\omega_{i t}+\eta_{i t},
$$

with $\omega_{i t}$ the transmitted component of the firm specific productivity shock, and $\eta_{i t}$ representing firm specific iid (unexpected) productivity shock or measurement errors.

As in Olley and Pakes (OP) (1996) or Levinsohn and Petrin (LP) (2003), Wooldridge (2009) expresses the transmitted component $\omega_{i t}$ as a function of the state variables and the a proxy variable. The proxy variable is investment in OP and intermediate inputs $m_{i t}$ in LP; as discussed in the text, we prefer the LP to OP because of the well-known lumpiness of investment in plantlevel data (as a result of which the investment proxy is in practice is missing for a number of observations). Thus for some function $g(.,$.$) :$

$$
\omega_{i t}=g\left(\mathbf{x}_{\mathbf{i t}}, m_{i t}\right), \quad t=1, \ldots, T,
$$


where $\mathbf{x}_{\mathbf{i t}}$ is the set of observed state variables. Typically, capital is considered as the state variable. In our context, because the job security laws introduce adjustments costs to labor, we include both blue and white collar labor in the set of state variables. So we have:

$$
\omega_{i t}=g\left(k_{i t}, l_{i t}^{u}, l_{i t}^{s}, m_{i t}\right), \quad t=1, \ldots, T .
$$

Another key idea in OP, LP and also in Ackerberg, Caves, Frazer (2006) is the assumption that the state variables are uncorrelated with the innovation:

$$
a_{i t}=\omega_{i t}-E\left(\omega_{i t} / \omega_{i t-1}\right) .
$$

Strengthening this with the assumption that lagged state and proxy variables are uncorrelated with the innovation yields a sufficient condition for recovering the production function parameters:

$$
E\left(\omega_{i t} \mid \mathbf{x}_{\mathbf{i t}}, \mathbf{w}_{\mathbf{i t}-\mathbf{1}}, m_{i t-1}, \ldots, \mathbf{w}_{\mathbf{1}}, \mathbf{x}_{\mathbf{1}}, m_{1}\right)=E\left(\omega_{i t} / \omega_{i t-1}\right) \equiv f\left[g\left(k_{i t-1}, l_{i t-1}^{u}, l_{i t-1}^{s}, m_{i t-1}\right)\right],
$$

where $\mathbf{w}_{\mathbf{i t}}$ denotes the vector of variable inputs (electricity and services). Note that the current, but not lagged, values of the variable inputs and the proxy are allowed to be correlated with the innovation. This then yields the following equation that identifies the production function parameters ${ }^{29}$

$$
q_{i t}=\beta_{s} l_{i t}^{s}+\beta_{u} l_{i t}^{u}+\beta_{k} k_{i t}+\beta_{m} m_{i t}+\beta_{e} e_{i t}+\beta_{v} v_{i t}+f\left[g\left(k_{i t-1}, l_{i t-1}^{u}, l_{i t-1}^{s}, m_{i t-1}\right)\right]+u_{i t},
$$

where $u_{i t} \equiv a_{i t}+\varepsilon_{i t}$. The moment conditions for identifying the parameters are:

$$
E\left(u_{i t} \mid \mathbf{x}_{\mathbf{i t}}, \mathbf{w}_{\mathbf{i t}-\mathbf{1}}, m_{i t-1}, \ldots, \mathbf{w}_{\mathbf{1}}, \mathbf{x}_{\mathbf{1}}, m_{1}\right)=0
$$

In our implementation, we approximate $f\left[g\left(k_{i t-1}, l_{i t-1}^{u}, l_{i t-1}^{s}, m_{i t-1}\right)\right]$ using a general second order polynomial. Also, as instruments (in addition to the exogenous state variables) we use first and second lags of electricity and services, and second order lags of blue and white collar labor.

The estimation is undertaken separately for each 3-digit industry. The coefficient estimates are summarized in Table A.2 ${ }^{30}$ These coefficient estimates appear reasonable, with materials predictably having the highest coefficient in all industries, followed generally by blue collar labor (or services in some cases), in line with the cost shares for these inputs. Capital estimates, which can be unreasonably low (or even negative) in some fixed effects estimations, are positive and bounded away from zero, except for 390 (Other manufacturing industries), where the estimate is close to zero (possibly because different types of plants get classified into this residual sector). The returns to scale is in the range of 0.82 to 1.06 , with all but two point estimates being below CRS. In the frictionless (zero adjustment cost) world, sufficient conditions for optimal input choice would require decreasing returns to scale. Assuming capital is semi-fixed, the returns to scale excluding capital is indeed less than one for all the industries (column 11). Our use of the flexible inputs (electricity and materials) as controls also assumes that second order conditions hold for these inputs conditional on others; hence it is reassuring that the sum of the coefficients on these flexible inputs (and services) is bounded well below one.

Generally under the Wooldridge (2009) approach (as in $\mathrm{OP} / \mathrm{LP} / \mathrm{ACF}$ ), there are more instruments than endogenous variables, yielding an overidentification test for the joint validity of the instruments. The results (p-value) of the overidentification test are reported in column 9; in none of the cases can the joint validity of the instruments be rejected at the $1 \%$ level. For most cases, the validity cannot be rejected at a cutoff of $10 \%$; in industry 321 and 390, the joint validity is questionable at the $5 \%$ cutoff level, and for industry 356 at the $10 \%$ level.

\footnotetext{
${ }^{29}$ This corresponds to equation 2.11 in Wooldridge (2009), which is the equation we use in our estimation.

${ }^{30}$ We exclude 5 small industries (which constituted less than $5.8 \%$ of total observations) where we found unreasonable (negative) coefficient estimates for one of the inputs.
} 


\section{C.2 Estimating Value Marginal Product and Gap}

Given the production function specification and observed input levels, the value marginal product is straightforward to calculate once one determines what "error" should be conditioned upon. The key issue is whether the $\eta_{i t}$ term is actual (but unpredicted) productivity or simply measurement error.

From the perspective of the PL aggregate productivity decomposition, if $\eta_{i t}$ is actual (but unexpected) productivity shock, the full error term $\left(\varepsilon_{i t}=\omega_{i t}+\eta_{i t}\right)$ is relevant, as there is no distinction in the measure between predictable versus unpredicted productivity shocks. In particular, a shift in resources from a firm with a negative gap to one with a positive gap would lead to greater aggregate productivity change, even if the negative and/or positive gaps arose because of unpredicted productivity shocks ${ }^{31}$ On the other hand, if $\eta_{i t}$ is mainly measurement error, then this does not reflect actual productivity and we should condition on $\omega_{i t}$ alone 32

As discussed in Section 7, in our baseline estimates, we condition on the full error term, and so a firm $i$ operating in year $t$ has a marginal product e.g., for skilled (white collar) labor given by:

$$
\frac{\partial Q_{i t}}{\partial L_{i t}^{s}}=\beta_{s} \cdot \frac{Q_{i t}}{L_{i t}^{s}},
$$

where $Q_{i t}$ is the real output measured as the firm revenue deflated by the industry price deflator. The price deflator multiplied by the marginal product yields the value of the marginal product for skilled labor:

$$
V M P_{i t}^{s}=P_{h t} \frac{\partial Q_{i t}}{\partial L_{i t}^{s}}=P_{h t} \beta_{s} \cdot \frac{Q_{i t}}{L_{i t}^{s}},
$$

where $\bar{P}_{h t}$ is the price deflator for the industry $h$ to which firm $i$ belongs. The derivation is very similar of the translog case, and we get:

$$
V M P_{i t}^{s}=P_{h t} \frac{\partial Q_{i t}}{\partial L_{i t}^{s}}=P_{h t} \beta_{s}^{T} \cdot \frac{Q_{i t}}{L_{i t}^{s}},
$$

where

$$
\beta_{s}^{T}=\frac{\partial q_{i t}}{\partial l_{i t}^{s}}=\beta_{s}+\beta_{s s} l_{i t}^{s}+\sum_{j \neq s} \beta_{j s} X_{i t}^{j},
$$

where $X$ demotes logged inputs (other than skilled labor).

As discussed in Section 4, the absolute gap can be obtained directly, once we have estimates for the VMP, following directly from the definitions. In particular, the absolute value of the gap between the value of the marginal product and marginal input price for input $\mathrm{j}$ is given by:

$$
G_{i t}^{j}=\left|V M P_{i t}^{j}-P_{i t}^{j}\right|
$$

where $p_{i t}^{j}$ denotes the price of input (wage rate in the case of labor; see Section 6 for definitions of the price variables).

The summary statistics on the input gaps by industry, as well as for the overall sample are presented in Appendix Table A.3. For almost all industries the gaps are larger for white collar

\footnotetext{
${ }^{31}$ Information technology or other innovations that allow firms to more accurately predict productivity shocks would thus improve allocative efficiency, per the PL measure.

${ }^{32}$ If the goal of the empirical exercise is to see if firms are optimizing (rather than to estimate changes to aggregate productivity), there is another reason to condition on $\omega_{i t}$. In many estimation methodologies (e.g Levinsohn and Petrin 2003, Olley and Pakes 1996), it is assumed that variable inputs (such as labor and materials) are chosen conditional on observing the transmitted component $\left(\omega_{i t}\right)$. Thus, profit-maximizing firms should be expected to equate the marginal product conditional on $\omega_{i t}$ to input prices. The marginal revenue conditional on $\hat{\omega}_{i t}$ is given by: $\beta_{s} * \frac{Q_{i t} e^{\left(\omega_{i t}\right)}}{l_{i t}^{s} e^{\left.\varepsilon_{i t}\right)}}$.
} 
relative to blue collar labor. The mean gap is are smaller than either blue or white collar labor labor for electricity, and negligible for materials. We find significant variation in input gaps across industry. For blue collar labor, the two industries with the highest mean estimated gap are 313 (Beverages) and 355 (Rubber products), and the two with the smallest mean gap are 322 (Apparel) and 324 (Footwear). For white collar gap, the largest mean gaps are for 356 (Plastic products) and 331(Wood products), and the smallest mean gaps are for 311(Food products) and 322 (Apparel).

\section{Appendix D: Construction of Capital Series}

For 1981 and 1982, the Chilean Manufacturing Census (Encuesta Nacional Industrial Anual) has book value of capital split into four categories - building, land, machinery and vehicles. For years 1992 to 1996, book value data is available for building, machinery and vehicles. In order to treat these series consistently, we aggregate land and building under "building" for years 1980 and 1981 as well.

Then for building, we construct first a series using the base year data for 1980 as follows:

$$
r b l d g_{t=1980}^{1980}=\frac{b^{b} b l d g_{1980}}{\text { defcons } s_{1980}},
$$

where $b v b l d g_{1980}$ is the book value for building for 1980, def cons $_{1980}$ is the base 1979 construction deflator so as to express values in (thousands of) 1979 pesos. Then for the years after 1980, the real building stock is constructed as:

$$
r b l d g_{t}^{1980}=r b l d g_{t-1}^{1980}\left(1-\delta_{b l d g}\right)+\left(\frac{I_{t}^{b l d g}}{\text { defcons }}\right),
$$

where the depreciation rate for building $\delta_{b l d g}$ is assumed to equal $5 \%$ (following Liu 1991), and $I_{t}^{b l d g}$ is the investment in building reported in year t. Following the same logic, for years prior to the base year 1980, the real capital series is constructed as:

$$
r b l d g_{t}^{1980}=\frac{1}{1-\delta_{b l d g}}\left(r b l d g_{t+1}^{1980}-\left(\frac{I_{t+1}^{b l d g}}{\text { defcons }_{t+1}}\right)\right) .
$$

The exact same procedure is followed to construct the real stock series for vehicles and machinery as well; the depreciation rate used for these series are $20 \%$ and $10 \%$ respectively, as in Liu (1991). The total real depreciated capital stock with base year 1980 is then the sum of the real depreciated stock of building, machinery and vehicles.

Next, following the same approach, we build separate series for building, machinery and vehicle stock using the 1981 and each of the 1992-1996 base years. Then, as discussed in Section 6.2. we construct a final data series using first the series with base 1980, and where plants have missing values (because the plant entered after 1980 or was missing in 1980), we replace missing values using the series for 1981, 1992, 1993, 1994, 1995 and 1996 in that order 33

\footnotetext{
${ }^{33}$ The computer code used to construct the capital series is available at: http://webuser.bus.umich.edu/jagadees/other/chile_code.htm
} 


\section{Figure 1 \\ Allocative Efficiency Gain from Eliminating a Positive Gap}

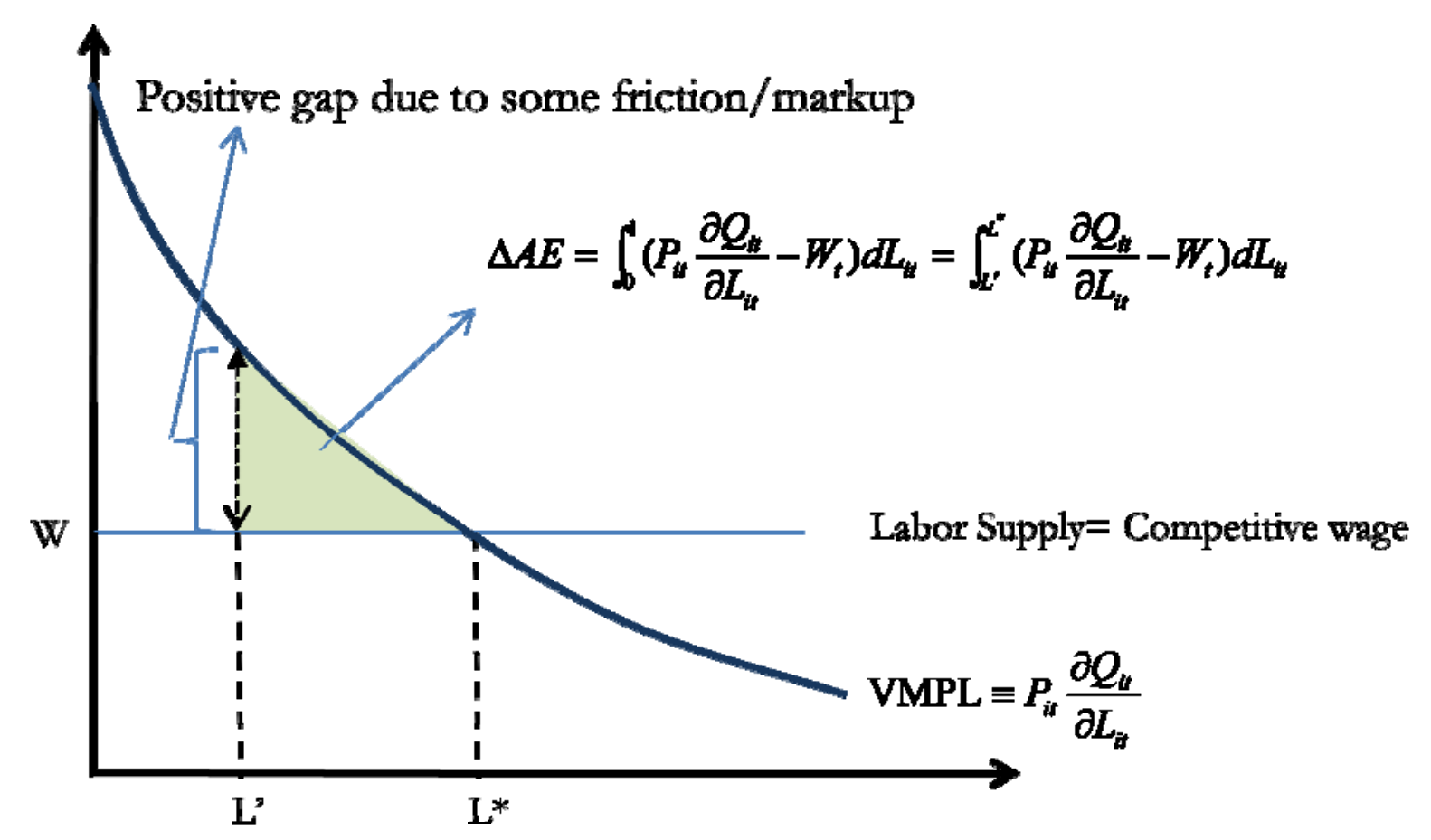

Suppose firm $i$ starts from an environment with a positive gap (induced by say firing costs, or a tax on wages, or markup), so labor is L'. Moving to an environment with zero gap (i.e. labor level $\mathrm{L}^{*}$ ) yields increase in allocative efficiency equal to the area below the VMPL curve and above the wage line. In the case of a gap induced only by markup, the allocative efficiency area corresponds to the standard Harberger deadweight triangle. 
Figure 2

Expected Discounted Cost of Firing a Worker

Multiples of monthly wages, Latin America and the IECD Countries, 1999

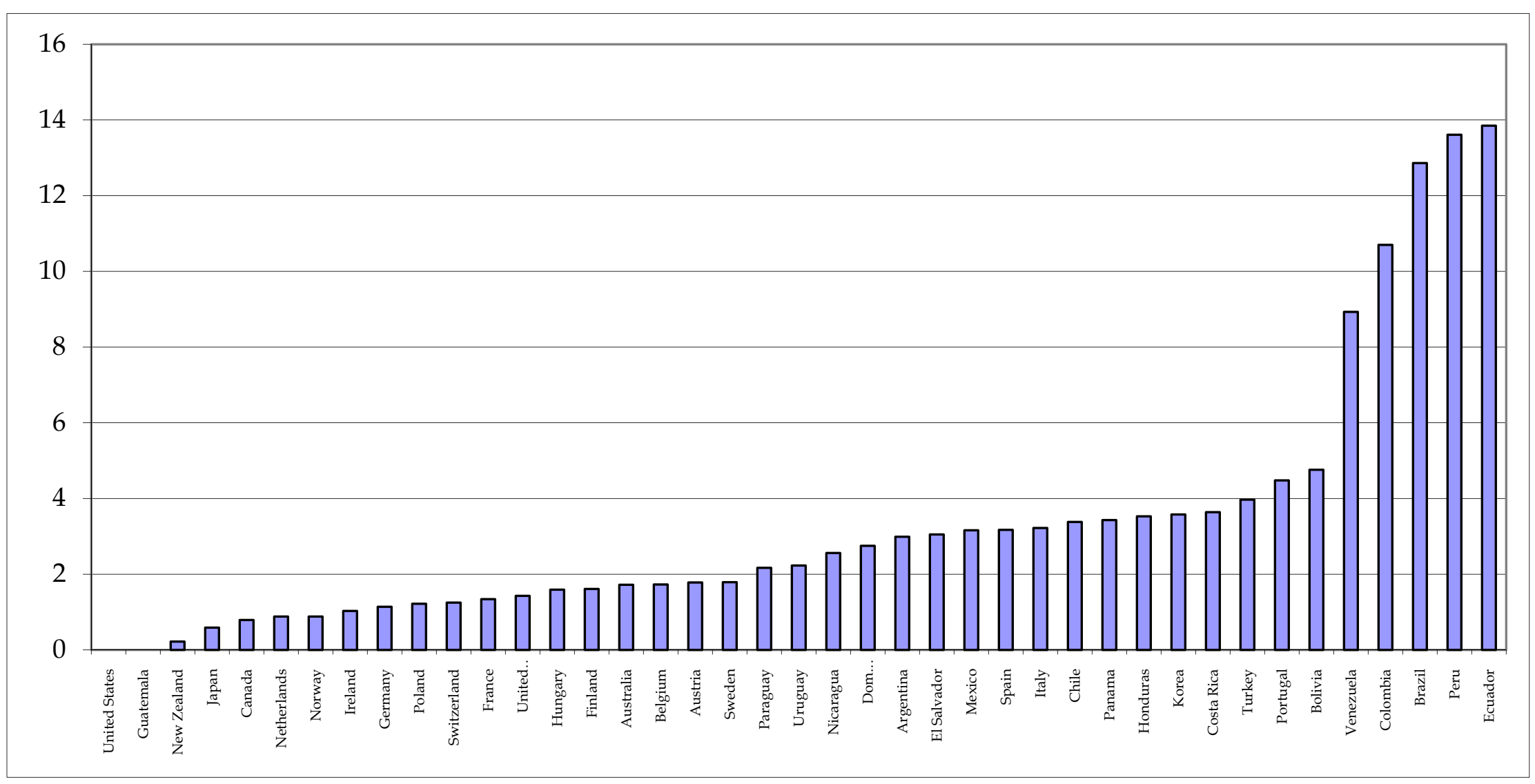

Source: Heckman and Pages (2004). Firing costs are defined as the additional payment made to the worker at the time of dismissal. This definition does not include "indirect" payments, like those made by U.S. firms into an insurance fund based in part on the number of firings at the firm. 
Figure 3

The Change in Firing Costs in Chile

Expected discounted cost of dismissing a worker, in multiples of monthly wages

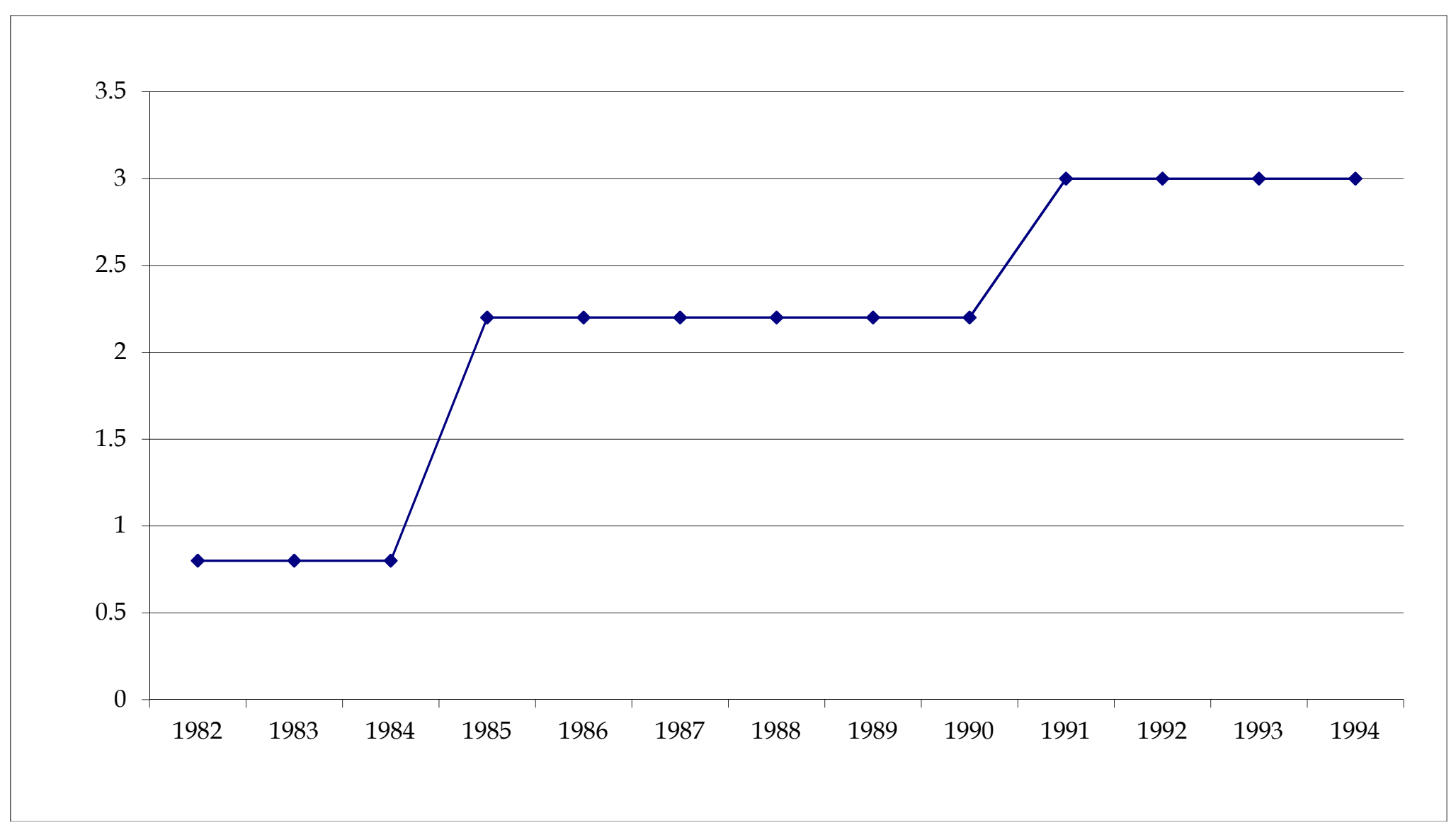

Source: Pages and Montenegro (1999) 


\section{Table 1}

The Absolute Value of the Gap

Between the Value of Marginal Product and the Input Price, 1982-1994

Simultaneity-Corrected Production Function Estimates, All Specifications include Firm Fixed Effects

\begin{tabular}{|c|c|c|c|c|c|c|c|c|}
\hline & \multicolumn{2}{|c|}{$\begin{array}{l}\text { Blue Collar } \\
\text { (1) }\end{array}$} & \multicolumn{2}{|c|}{ White Collar } & \multicolumn{2}{|c|}{ Materials } & \multicolumn{2}{|c|}{$\begin{array}{l}\text { Electricity } \\
\text { (7) }\end{array}$} \\
\hline Base Period Gap (1982-1984) & $\begin{array}{r}83.42^{* * *} \\
{[6.620]}\end{array}$ & $\begin{array}{r}83.77^{* * *} \\
{[6.622]}\end{array}$ & $\begin{array}{r}138.6^{* * *} \\
{[5.488]}\end{array}$ & $\begin{array}{r}138.9^{* * *} \\
{[5.435]}\end{array}$ & $\begin{array}{r}0.357^{* * *} \\
{[0.00985]}\end{array}$ & $\begin{array}{r}0.356^{* * *} \\
{[0.00995]}\end{array}$ & $\begin{array}{r}21.11^{* * *} \\
{[0.886]}\end{array}$ & $\begin{array}{r}21.22^{* * *} \\
{[0.887]}\end{array}$ \\
\hline Increase in Gap, 2nd Pd. (85-90) & $\begin{array}{r}23.47^{* * *} \\
{[8.713]}\end{array}$ & $\begin{array}{l}22.99^{* *} \\
{[8.682]}\end{array}$ & $\begin{array}{l}17.98^{* *} \\
{[7.387]}\end{array}$ & $\begin{array}{l}17.56^{* *} \\
{[7.257]}\end{array}$ & $\begin{array}{r}-0.0403^{* * *} \\
{[0.0143]}\end{array}$ & $\begin{array}{r}-0.0392^{* * *} \\
{[0.0144]}\end{array}$ & $\begin{array}{r}-0.563 \\
{[0.997]}\end{array}$ & $\begin{array}{r}-0.718 \\
{[0.996]}\end{array}$ \\
\hline Increase in Gap, 3rd Pd. (91-94) & $\begin{array}{r}25.58^{* * *} \\
{[9.038]}\end{array}$ & $\begin{array}{r}25.14^{* * *} \\
{[9.066]}\end{array}$ & $\begin{array}{r}23.87^{* * *} \\
{[7.922]}\end{array}$ & $\begin{array}{r}23.48^{* * *} \\
{[7.916]}\end{array}$ & $\begin{array}{r}-0.0324^{* * *} \\
{[0.0118]}\end{array}$ & $\begin{array}{r}-0.0314^{* *} \\
{[0.0121]}\end{array}$ & $\begin{array}{r}-2.211 \\
{[1.339]}\end{array}$ & $\begin{array}{l}-2.356^{*} \\
{[1.345]}\end{array}$ \\
\hline Industry Output Growth Rate & & $\begin{array}{r}2.201 \\
{[1.904]}\end{array}$ & & $\begin{array}{r}1.93 \\
{[2.076]}\end{array}$ & & $\begin{array}{r}-0.00488 \\
{[0.0145]}\end{array}$ & & $\begin{array}{r}0.713 \\
{[0.540]}\end{array}$ \\
\hline Observations & 43,675 & 43,675 & 43,675 & 43,675 & 43,675 & 43,675 & 43,675 & 43,675 \\
\hline R-squared & 0.791 & 0.791 & 0.653 & 0.653 & 0.504 & 0.504 & 0.589 & 0.589 \\
\hline
\end{tabular}

All gaps are in thousands of 1979 pesos (deflator used is the CPI). Marginal product estimates are from a gross output (revenue deflated by industry-specific deflators) Cobb-Douglas production function specification, which is estimated using Wooldridge (2009) modification of the Levinsohn-Petrin (2003) approach to address the simultaneous determination of inputs and productivity. The blue-collar input price is the total blue-collar wage bill divided by the number of blue-collar employees. We define the white collar input price similarly. For materials we use a 3digit industry-specific price index. Electricity prices are derived from establishment-specific quantity and value information. We estimate production functions separately for each 3-digit industry. Standard errors (reported in brackets) are clustered at the 4-digit industry level. * significant at $10 \%$; ** significant at $5 \%$; *** significant at $1 \%$. 


\section{Figure 4 \\ Average Absolute Gap: Blue and White Collar Labor}

95\% Confidence Interval for Change in Gap

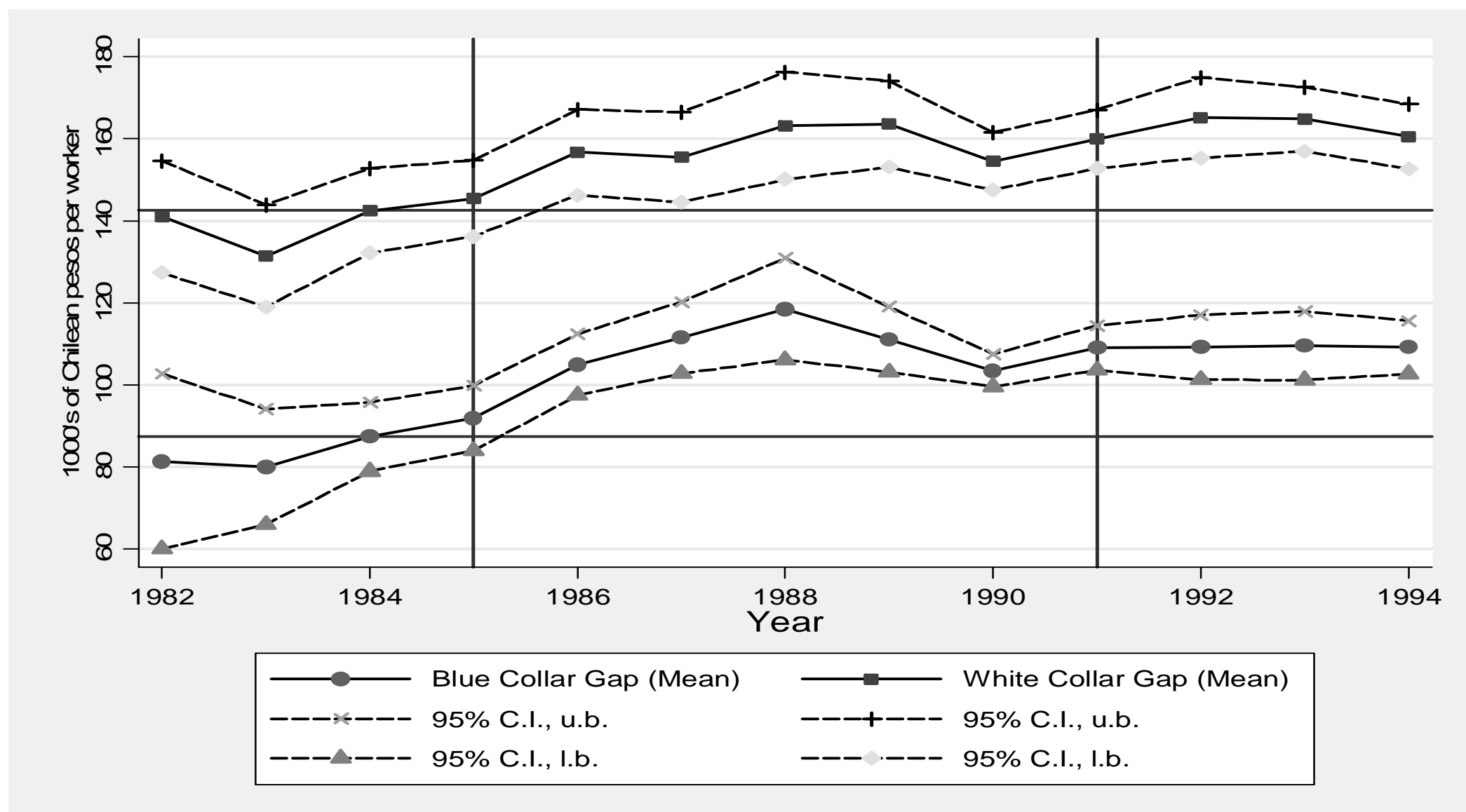

All gaps are in thousands of 1979 pesos (deflator used is the CPI). Gaps are those implied by the Wooldridge (2009) modification of the LevinsohnPetrin (2003) estimator. The figure plots the coefficients from the regression of the absolute value of the gaps on yearly indicator variables, plantlevel fixed effects, and the industry output growth rate. The two lines demark the level of the average gap for blue and white collar labor in 1984, so the years for which the line is not within the confidence interval are the years for which the change in the gap is significantly different from the 1984 gap. Standard errors are clustered at the 4-digit industry level. 


\section{Table 2}

The Gap between the Marginal Revenue Product and the Input Price, 1982-1994

Simultaneity-Corrected Revenue Function Estimates, All Specifications include Firm Fixed Effects

\begin{tabular}{lrrrr}
\hline & \multicolumn{2}{c}{ Materials } & \multicolumn{2}{c}{ Electricity } \\
& $(1)$ & \multicolumn{1}{c}{$(2)$} & \multicolumn{1}{c}{$(3)$} & \multicolumn{1}{c}{$(4)$} \\
\hline & & & & \\
Base Period Gap (1982-1984) & $0.348^{* * *}$ & $0.343^{* * *}$ & $21.71^{* * *}$ & $22.05^{* * *}$ \\
& {$[0.00711]$} & {$[0.00720]$} & {$[0.970]$} & {$[0.988]$} \\
Increase in Gap, 2nd Pd. (85-90) & -0.0145 & -0.00728 & 1.349 & 0.864 \\
& {$[0.00896]$} & {$[0.00792]$} & {$[0.996]$} & {$[1.002]$} \\
Increase in Gap, 3rd Pd. (91-94) & -0.0107 & -0.00384 & -2.181 & -2.644 \\
& {$[0.0142]$} & {$[0.0149]$} & {$[1.548]$} & {$[1.584]$} \\
Industry Output Growth Rate & & $-0.0370^{* *}$ & & $2.485^{*}$ \\
& & {$[0.0169]$} & & {$[1.396]$} \\
Observations & 43,302 & 43,302 & 43,302 & 43,302 \\
R-squared & 0.503 & 0.503 & 0.588 & 0.588 \\
\hline
\end{tabular}

Marginal revenue product estimates are from a Cobb-Douglas revenue (deflated by CPI) function specification, which is estimated using Wooldridge (2009) modification of the Levinsohn-Petrin (2003) approach to address the simultaneous determination of inputs and productivity/demand. All gaps are in thousands of 1979 pesos (deflator used is the CPI). In all cases, we estimate revenue functions separately for each 3-digit industry. See notes to Table 1 for definitions of input prices. Standard errors (reported in brackets) are clustered at the 4-digit industry level. * significant at $10 \%$; ${ }^{* *}$ significant at $5 \%$; *** significant at $1 \%$. 


\section{Figure 5}

Trends in the Average Absolute Gap (Normalized) Blue and White Collar Labor, Materials, and Electricity

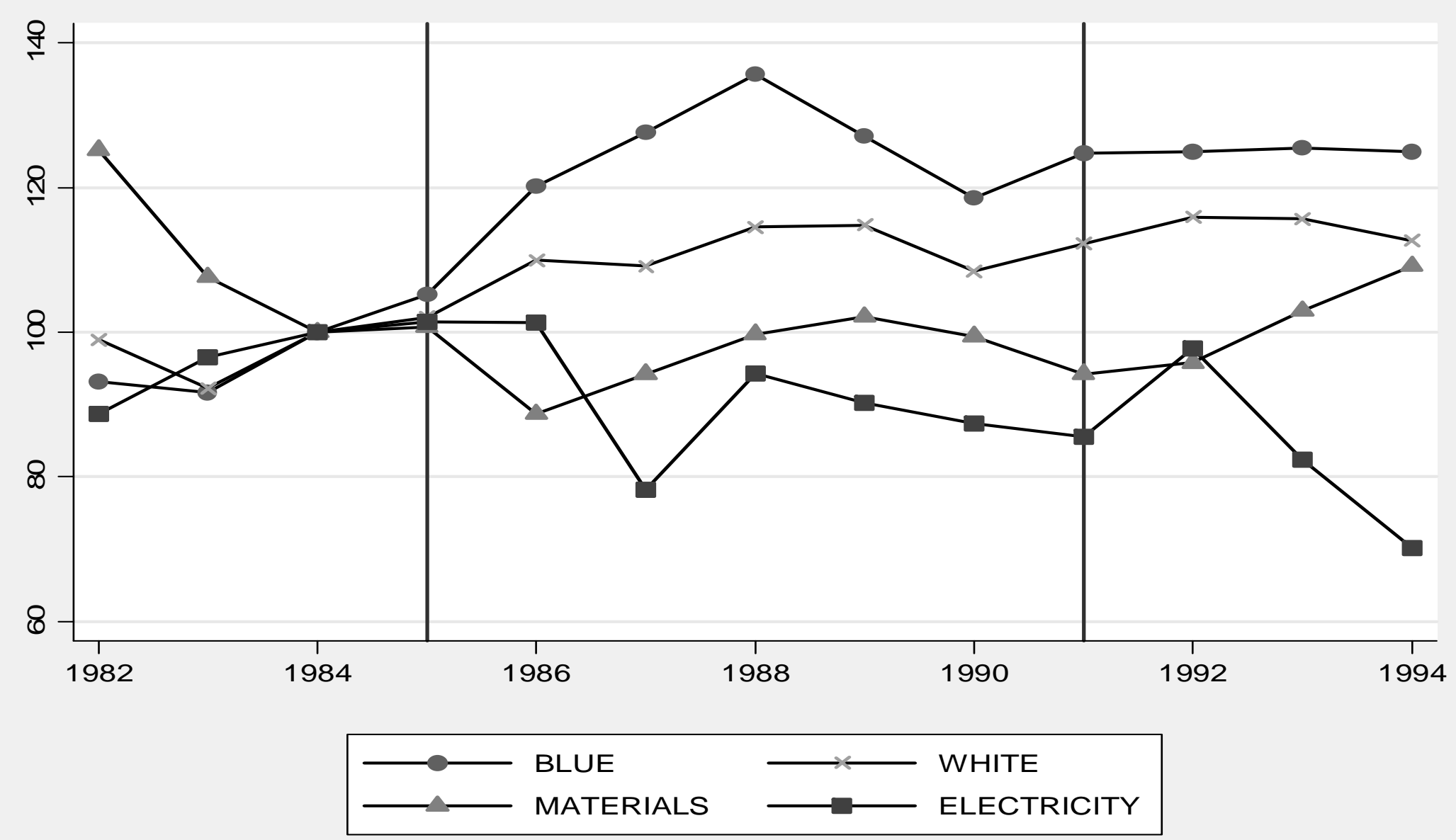

The graph plots the coefficient on year dummies in regression of absolute gap between marginal product of an input and its normalized price. Gaps are those implied by the Wooldridge (2009) modification of the Levinsohn-Petrin (2003) estimator. The regressions include firm fixed effects and industry output growth rate. Year 1984 is normalized to 100. 


\section{Table 3}

The Gap between the Value of Marginal Product and the Input Price, 1982-1994

Robustness to Alternative Production Function Specifications

Simultaneity-Corrected Production Function Estimates, All Specifications include Plant Fixed Effects

\begin{tabular}{|c|c|c|c|c|c|c|c|c|}
\hline & \multicolumn{4}{|c|}{ Cobb-Douglas OLS Fixed Effects } & \multicolumn{4}{|c|}{ Translog (Order 2) Fixed Effects } \\
\hline & \multicolumn{2}{|c|}{ Blue Collar White Collar } & \multirow{2}{*}{$\begin{array}{r}\text { Materials } \\
(3) \\
\end{array}$} & \multirow{2}{*}{$\begin{array}{r}\text { Electricity } \\
(4) \\
\end{array}$} & \multicolumn{2}{|c|}{ Blue Collar White Collar } & \multirow{2}{*}{$\begin{array}{r}\text { Materials } \\
(7) \\
\end{array}$} & \multirow{2}{*}{$\begin{array}{r}\text { Electricity } \\
(8) \\
\end{array}$} \\
\hline & $(1)$ & $(2)$ & & & $(5)$ & $(6)$ & & \\
\hline Base Period Gap (1982-1984) & $\begin{array}{r}111.2^{* * *} \\
{[8.618]}\end{array}$ & $\begin{array}{r}162.9^{* * *} \\
{[5.579]}\end{array}$ & $\begin{array}{l}0.330^{* * *} \\
{[0.0082]}\end{array}$ & $\begin{array}{r}14.11^{* * *} \\
{[0.480]}\end{array}$ & $\begin{array}{r}89.31^{\star * *} \\
{[4.367]}\end{array}$ & $\begin{array}{r}146.2^{* * *} \\
{[5.695]}\end{array}$ & $\begin{array}{c}0.266^{* * *} \\
{[0.006]}\end{array}$ & $\begin{array}{r}15.76^{* * *} \\
{[0.537]}\end{array}$ \\
\hline Increase in Gap, 2nd Pd. (85-90) & $\begin{array}{r}36.88^{* * *} \\
{[10.56]}\end{array}$ & $\begin{array}{r}32.62^{* * *} \\
{[6.667]}\end{array}$ & $\begin{array}{r}-0.0234 \\
{[0.0147]}\end{array}$ & $\begin{array}{r}-0.579 \\
{[0.587]}\end{array}$ & $\begin{array}{r}22.88^{* * *} \\
{[5.687]}\end{array}$ & $\begin{array}{r}25.17^{* * *} \\
{[6.496]}\end{array}$ & $\begin{array}{r}-0.023^{* * *} \\
{[0.007]}\end{array}$ & $\begin{array}{r}1.018 \\
{[0.638]}\end{array}$ \\
\hline Increase in Gap, 3rd Pd. (91-94) & $\begin{array}{r}33.60^{* * *} \\
{[12.45]}\end{array}$ & $\begin{array}{r}26.32^{* * *} \\
{[8.873]}\end{array}$ & $\begin{array}{r}-0.0215^{* *} \\
{[0.010]}\end{array}$ & $\begin{array}{r}-1.778^{* *} \\
{[0.686]}\end{array}$ & $\begin{array}{r}18.86^{* * *} \\
{[5.811]}\end{array}$ & $\begin{array}{r}32.75^{* * *} \\
{[8.511]}\end{array}$ & $\begin{array}{r}-0.0180^{* *} \\
{[0.008]}\end{array}$ & $\begin{array}{r}1.02 \\
{[0.820]}\end{array}$ \\
\hline Industry Output Growth Rate & $\begin{array}{r}9.43 \\
{[5.690]}\end{array}$ & $\begin{array}{r}11.67 \\
{[7.810]}\end{array}$ & $\begin{array}{r}-0.0312 \\
{[0.0200]}\end{array}$ & $\begin{array}{r}1.404 \\
{[0.914]}\end{array}$ & $\begin{array}{r}2.843^{*} \\
{[1.476]}\end{array}$ & $\begin{array}{l}5.667^{* *} \\
{[2.369]}\end{array}$ & $\begin{array}{r}0.000 \\
{[0.009]}\end{array}$ & $\begin{array}{r}0.191 \\
{[0.554]}\end{array}$ \\
\hline Observations & 41,067 & 41,067 & 41,067 & 41,067 & 46,353 & 46,353 & 46,353 & 46,353 \\
\hline R-squared & 0.801 & 0.655 & 0.502 & 0.599 & 0.721 & 0.646 & 0.525 & 0.575 \\
\hline
\end{tabular}

All gaps are in thousands of 1979 pesos (deflator used is the CPI). In columns 1 to 4, the marginal product estimates are from a gross output CobbDouglas production function specification, which is estimated using OLS with plant-period fixed effects. In columns 5 to 8 , the marginal product estimates are from a gross output Translog (order 2) production function specification, which is estimated using OLS with plant-period fixed effects. In all cases, we estimate production functions separately for each 3-digit industry. See notes to Table 1 for definitions of input prices. Standard errors (reported in brackets) are clustered at the 4-digit industry level. * significant at $10 \%$; ${ }^{* *}$ significant at $5 \%$; ${ }^{* *}$ significant at $1 \%$. 


\section{Table 4}

The Gap between the Value of Marginal Product and the Wages, 1982-1994

Robustness to using Transmitted Component of the Error Term

Simultaneity-Corrected Production Function Estimates, All Specifications include Plant Fixed Effects

\begin{tabular}{lrrrr}
\hline & \multicolumn{4}{c}{ Using Transmitted Component of Error } \\
\cline { 2 - 5 } & Blue Collar & White Collar & Materials & Electricity \\
& $(1)$ & $(2)$ & $(3)$ & $(4)$ \\
Base Period Gap (1982-1984) & & & & \\
& $83.89^{* * *}$ & $138.8^{* * *}$ & $0.276^{* * *}$ & $21.14^{* * *}$ \\
Increase in Gap, 2nd Pd. (85-90) & {$[5.596]$} & {$[5.092]$} & {$[0.00988]$} & {$[0.819]$} \\
& $20.74^{* * *}$ & $16.46^{* *}$ & $-0.0240^{* *}$ & -0.383 \\
Increase in Gap, 3rd Pd. (91-94) & {$[7.327]$} & {$[6.851]$} & {$[0.0116]$} & {$[0.863]$} \\
& $19.78^{* *}$ & $18.21^{* *}$ & $-0.0395^{* * *}$ & $-3.284^{* *}$ \\
Industry Output Growth Rate & {$[7.779]$} & {$[7.544]$} & {$[0.0141]$} & {$[1.324]$} \\
Observations & 2.053 & 1.748 & $-0.0165^{* *}$ & 0.566 \\
R-squared & {$[1.659]$} & {$[2.107]$} & {$[0.00628]$} & {$[0.522]$} \\
\hline
\end{tabular}

All gaps are in thousands of 1979 pesos (deflator used is the CPI). Marginal product estimates are from a gross output Cobb-Douglas production function specification, which is estimated using Wooldridge (2009) modification of the Levinsohn-Petrin (2003) approach to address the

simultaneous determination of inputs and productivity. To calculate the marginal product, the transmitted component of the error term is used. See notes to Table 1 for definitions of input prices. Standard errors (reported in brackets) are clustered at the 4-digit industry level. * significant at $10 \%$; ** significant at $5 \%$; *** significant at $1 \%$. 


\section{Table 5}

The Gap between the Value of Marginal Product and the Input Price, 1982-1994

Robustness to using alternative wage measure and using positive gaps only

Simultaneity-Corrected Production Function Estimates, All Specifications include Plant Fixed Effects

\begin{tabular}{|c|c|c|c|c|c|c|c|c|}
\hline & \multicolumn{4}{|c|}{ Alternative wage measure } & \multicolumn{4}{|c|}{ Positive gaps only } \\
\hline & \multicolumn{2}{|c|}{ Blue Collar } & \multicolumn{2}{|c|}{ White Collar } & \multicolumn{2}{|c|}{ Blue Collar } & \multicolumn{2}{|c|}{ White Collar } \\
\hline & (1) & $(2)$ & (3) & (4) & (5) & (6) & (7) & $(8)$ \\
\hline Base Period Gap (1982-1984) & $\begin{array}{r}100.8^{* * *} \\
{[4.577]}\end{array}$ & $\begin{array}{r}100.2^{* * *} \\
{[3.928]}\end{array}$ & $\begin{array}{r}196.0 * * * \\
{[9.992]}\end{array}$ & $\begin{array}{r}199.6^{* * *} \\
{[11.91]}\end{array}$ & $\begin{array}{r}109.1^{* * *} \\
{[6.682]}\end{array}$ & $\begin{array}{r}111.1^{* * *} \\
{[6.721]}\end{array}$ & $\begin{array}{r}145.3^{* * *} \\
{[10.23]}\end{array}$ & $\begin{array}{r}145.8^{* * *} \\
{[10.23]}\end{array}$ \\
\hline Increase in Gap, 2nd Pd. (85-90) & $\begin{array}{l}16.23^{* *} \\
{[6.556]}\end{array}$ & $\begin{array}{r}17.02^{* * *} \\
{[5.599]}\end{array}$ & $\begin{array}{r}7.737 \\
{[15.73]}\end{array}$ & $\begin{array}{r}2.500 \\
{[18.76]}\end{array}$ & $\begin{array}{r}44.79 * * * \\
{[6.962]}\end{array}$ & $\begin{array}{r}41.46^{* * *} \\
{[6.856]}\end{array}$ & $\begin{array}{r}44.90^{* * *} \\
{[12.46]}\end{array}$ & $\begin{array}{r}44.09^{* * *} \\
{[12.41]}\end{array}$ \\
\hline Increase in Gap, 3rd Pd. (91-94) & $\begin{array}{r}37.46^{* * *} \\
{[7.167]}\end{array}$ & $\begin{array}{r}38.17^{* * *} \\
{[6.664]}\end{array}$ & $\begin{array}{r}55.37^{* * *} \\
{[11.33]}\end{array}$ & $\begin{array}{r}50.62^{* * *} \\
{[13.14]}\end{array}$ & $\begin{array}{r}44.24^{* * *} \\
{[11.50]}\end{array}$ & $\begin{array}{r}41.44^{* * *} \\
{[11.71]}\end{array}$ & $\begin{array}{r}41.44^{* * *} \\
{[14.29]}\end{array}$ & $\begin{array}{r}40.72^{* * *} \\
{[14.36]}\end{array}$ \\
\hline Industry Output Growth Rate & & $\begin{array}{r}-4.04 \\
{[11.68]}\end{array}$ & & $\begin{array}{r}24.75 \\
{[22.85]}\end{array}$ & & $\begin{array}{r}19.52^{* * *} \\
{[7.137]}\end{array}$ & & $\begin{array}{r}4.493 \\
{[3.625]}\end{array}$ \\
\hline Observations & 43,346 & 43,346 & 43,502 & 43,502 & 26,949 & 26,949 & 27,208 & 27,208 \\
\hline$\underline{\text { R-squared }}$ & 0.736 & 0.736 & 0.525 & 0.525 & 0.803 & 0.804 & 0.684 & 0.684 \\
\hline $\begin{array}{l}\text { All gaps are in thousands of } 1979 \\
\text { the changes in employment and } \\
\text { have positive gaps - for these cas } \\
\text { (revenue deflated by industry-spe } \\
\text { modification of the Levinsohn-Pe } \\
\text { price is the total blue-collar wage } \\
\text { materials we use a 3-digit industr } \\
\text { We estimate production functions } \\
\text { level. * significant at 10\%; ** signi }\end{array}$ & $\begin{array}{l}\text { leflator us } \\
\text { at firms i } \\
\text { urement } \\
\text { flators) Co } \\
\text { 3) approa } \\
\text { ded by th } \\
\text { ic price in } \\
\text { tely for ea } \\
5 \% \text {; }{ }^{* * *} \mathrm{si}\end{array}$ & $\begin{array}{l}\text { is the CPI). } \\
\text { easing emp } \\
r \text { in wages } \\
\text { Douglas } p \\
\text { o address } \\
\text { mber of } b \\
\text { Electricit } \\
\text {-digit ind }\end{array}$ & $\begin{array}{l}\text { ses the gap } \\
\text { uction fun } \\
\text { simultanec } \\
\text { collar emp } \\
\text { ices are de } \\
\text {. Standarc }\end{array}$ & $\begin{array}{l}\text { ve use as } \\
\text { st } 10 \% \text {. . } \\
\text { wnwards } \\
\text { n specific } \\
\text { determin } \\
\text { ees. We d } \\
\text { ed from e } \\
\text { ors (repo }\end{array}$ & $\begin{array}{l}\text { lternative } \\
\text { lumns 5-£ } \\
\text { arginal pr } \\
\text { n, which i } \\
\text { of input } \\
\text { e the whit } \\
\text { lishment- } \\
\text { in bracke }\end{array}$ & $\begin{array}{l}\text { ustry-leve } \\
\text { use only } \\
\text { t estimat } \\
\text { mated us } \\
\text { I product } \\
\text { lar input } \\
\text { fic quant } \\
\text { re cluster }\end{array}$ & $\begin{array}{l}\text { age meast } \\
\text { se observa } \\
\text { re from a } \\
\text { Wooldrid } \\
\text {. The blue } \\
\text { e similarl } \\
\text { nd value } \\
\mathrm{t} \text { the } 4 \text {-dis }\end{array}$ & $\begin{array}{l}\text { ased on } \\
\text { s that } \\
\text { soutput } \\
\text { 2009) } \\
\text { lar input } \\
\text { r } \\
\text { mation. } \\
\text { dustry }\end{array}$ \\
\hline
\end{tabular}




\section{Table 6}

The Gap between the Value of Marginal Product and the Wages, 1982-1994 Sample-splitting Test based on Excess Worker Turnover

Simultaneity-Corrected Production Function Estimates, All Specifications include Plant Fixed Effects

\begin{tabular}{|c|c|c|c|c|c|c|c|c|}
\hline & \multicolumn{2}{|c|}{ Blue Collar } & \multicolumn{2}{|c|}{ White Collar } & \multicolumn{2}{|c|}{ Materials } & \multicolumn{2}{|c|}{ Electricity } \\
\hline & $\begin{array}{l}\text { Above } \\
\text { median }\end{array}$ & $\begin{array}{c}\text { Below } \\
\text { median }\end{array}$ & $\begin{array}{l}\text { Above } \\
\text { median }\end{array}$ & $\begin{array}{c}\text { Below } \\
\text { median }\end{array}$ & $\begin{array}{l}\text { Above } \\
\text { median }\end{array}$ & $\begin{array}{c}\text { Below } \\
\text { median }\end{array}$ & $\begin{array}{l}\text { Above } \\
\text { median }\end{array}$ & $\begin{array}{l}\text { Below } \\
\text { median }\end{array}$ \\
\hline & (1a) & $(1 \mathrm{~b})$ & $(2 a)$ & $(2 b)$ & $(3 a)$ & $(3 b)$ & $(4 a)$ & $(4 \mathrm{~b})$ \\
\hline Base Period Gap (1982-1984) & $\begin{array}{r}69.48^{* * *} \\
{[8.157]}\end{array}$ & $\begin{array}{r}114.0^{* * * *} \\
{[6.995]}\end{array}$ & $\begin{array}{r}116.7^{* * *} \\
{[6.453]}\end{array}$ & $\begin{array}{r}185.2^{* * *} \\
{[9.019]}\end{array}$ & $\begin{array}{l}0.325^{* * *} \\
{[0.0130]}\end{array}$ & $\begin{array}{l}0.415^{* * *} \\
{[0.0136]}\end{array}$ & $\begin{array}{r}20.79 * * * \\
{[0.819]}\end{array}$ & $\begin{array}{r}22.61^{* * *} \\
{[1.223]}\end{array}$ \\
\hline Increase in Gap, 2nd Pd. (85-90) & $\begin{array}{r}18.28 \\
{[10.73]}\end{array}$ & $\begin{array}{r}29.71^{* * *} \\
{[8.193]}\end{array}$ & $\begin{array}{c}14.16^{*} \\
{[7.305]}\end{array}$ & $\begin{array}{r}21.34 \\
{[14.86]}\end{array}$ & $\begin{array}{r}-0.0388^{* *} \\
{[0.0188]}\end{array}$ & $\begin{array}{r}-0.0341 \\
{[0.0201]}\end{array}$ & $\begin{array}{l}-1.783^{*} \\
{[0.946]}\end{array}$ & $\begin{array}{r}0.731 \\
{[1.272]}\end{array}$ \\
\hline Increase in Gap, 3rd Pd. (91-94) & $\begin{array}{c}19.54^{*} \\
{[11.04]}\end{array}$ & $\begin{array}{r}34.78^{* * *} \\
{[11.65]}\end{array}$ & $\begin{array}{c}20.60^{*} \\
{[10.38]}\end{array}$ & $\begin{array}{r}27.40^{* * * *} \\
{[9.476]}\end{array}$ & $\begin{array}{l}-0.0328^{*} \\
{[0.0163]}\end{array}$ & $\begin{array}{r}-0.0257 \\
{[0.0167]}\end{array}$ & $\begin{array}{r}-3.912^{* * *} \\
{[1.261]}\end{array}$ & $\begin{array}{r}0.00538 \\
{[1.966]}\end{array}$ \\
\hline Industry Output Growth Rate & $\begin{array}{r}0.311 \\
{[0.561]}\end{array}$ & $\begin{array}{l}18.44^{* *} \\
{[6.835]}\end{array}$ & $\begin{array}{l}0.0446 \\
{[0.869]}\end{array}$ & $\begin{array}{c}17.95^{*} \\
{[9.985]}\end{array}$ & $\begin{array}{r}-0.00141 \\
{[0.0135]}\end{array}$ & $\begin{array}{r}-0.0348 \\
{[0.0213]}\end{array}$ & $\begin{array}{r}0.406 \\
{[0.356]}\end{array}$ & $\begin{array}{r}3.219^{* * * *} \\
{[0.951]}\end{array}$ \\
\hline Observations & 29,151 & 14,524 & 29,151 & 14,524 & 29,151 & 14,524 & 29,151 & 14,524 \\
\hline R-squared & 0.807 & 0.773 & 0.645 & 0.648 & 0.514 & 0.484 & 0.549 & 0.651 \\
\hline
\end{tabular}

Excess worker turnover is defined as total worker turnover less job turnover normalized by employment, and is defined using 3-digit SIC code Quarterly Workforce Indicators (QWI) data for the United States. All gaps are in thousands of 1979 pesos (deflator used is the CPI). Marginal product estimates are from a gross output Cobb-Douglas production function specification, which is estimated using Wooldridge (2009)

modification of the Levinsohn-Petrin (2003) approach to address the simultaneous determination of inputs and productivity. See notes to Table 1 for definitions of input prices. Standard errors (reported in brackets) are clustered at the 4-digit industry level. * significant at $10 \%$; ** significant at $5 \%$; *** significant at $1 \%$. 
Figure A.1

\section{Trends in Real Wages}

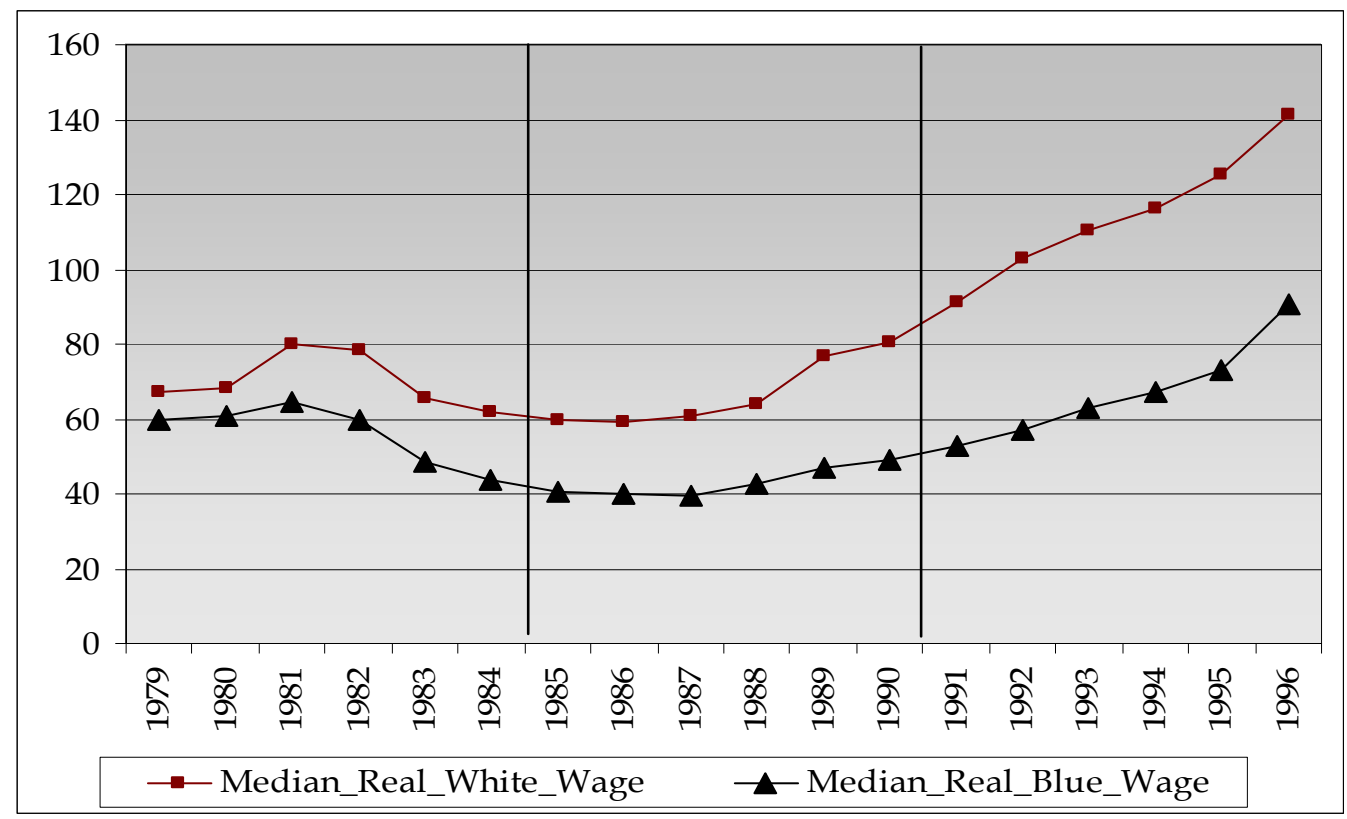

Source: Authors' calculations

Figure A.2

\section{Inflation and Unemployment Rate}

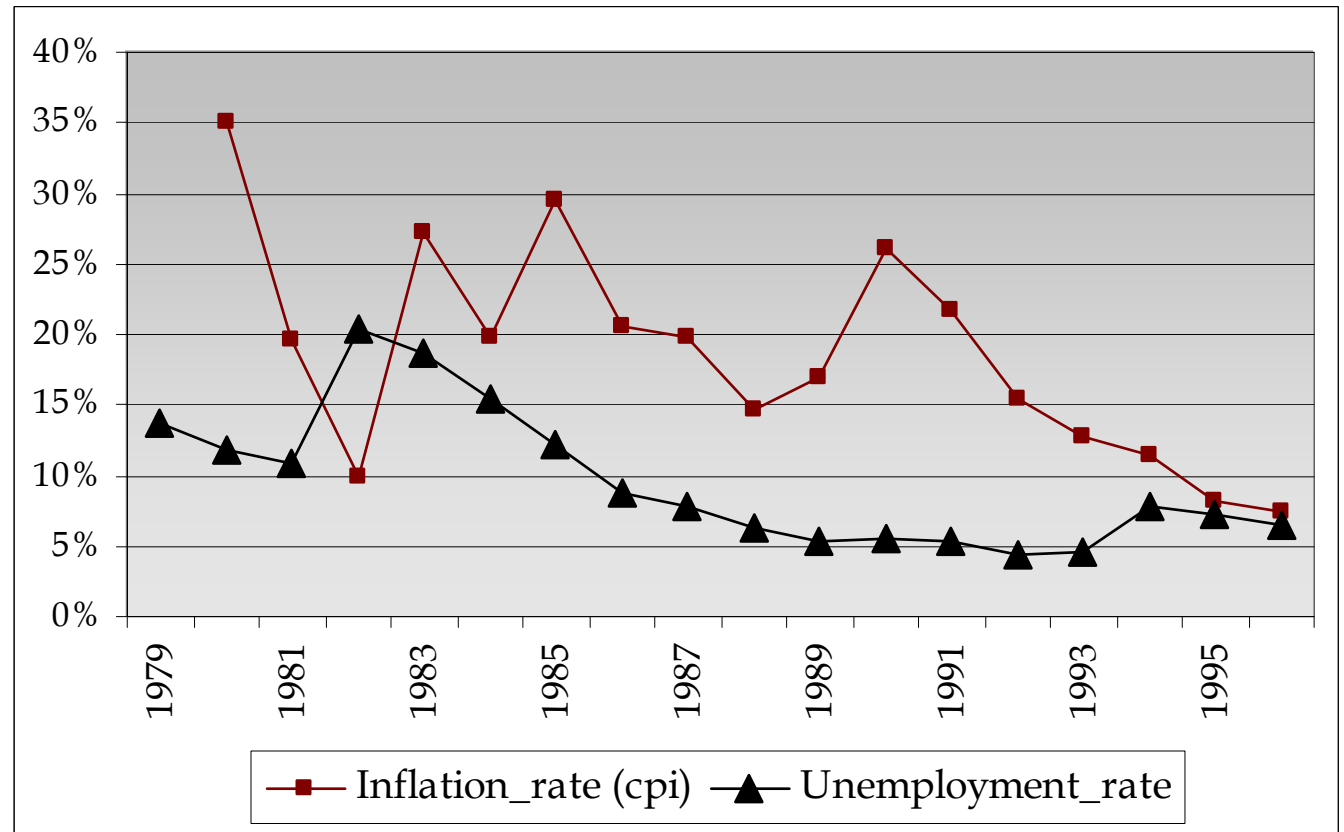

Source: Edwards \& Edwards (2000), ILO statistics, authors' calculations 
Figure A.3

Manufacturing Growth (From IMF IFS database)

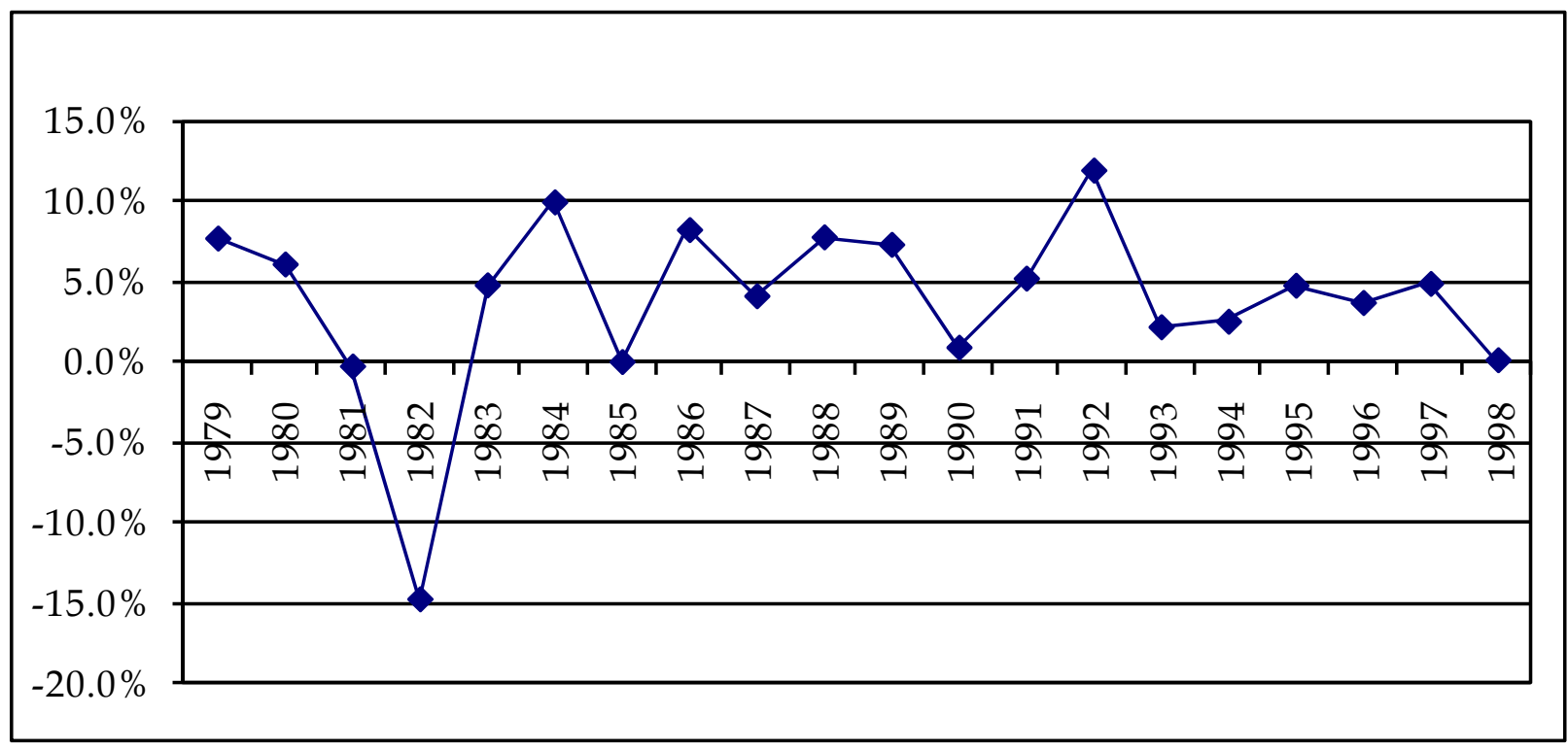




\section{Table A.1}

\section{Explaining Movements in Real Wages}

\begin{tabular}{|c|c|c|c|c|c|}
\hline & (1) & (2) & (3) & (4) & (5) \\
\hline \multirow[t]{2}{*}{ Period Dummy (1985-1990) } & -0.37 & -0.37 & -0.40 & -0.36 & -0.53 \\
\hline & {$[0.02]^{* *}$} & {$[0.02]^{* *}$} & {$[0.02]^{* *}$} & {$[0.02]^{* *}$} & {$[0.02]^{* *}$} \\
\hline \multirow[t]{2}{*}{ Period Dummy (1991-1996) } & 0.081 & 0.072 & -0.007 & 0.092 & -0.112 \\
\hline & {$[0.02]^{* *}$} & {$[0.02]^{* *}$} & {$[0.02]$} & {$[0.02]^{* *}$} & {$[0.02]^{* *}$} \\
\hline \multirow[t]{2}{*}{ Firm Output Growth Rate } & & 0.008 & & & \\
\hline & & {$[0.002]^{* *}$} & & & \\
\hline \multirow[t]{2}{*}{ Log(Industry Output) } & & & 0.127 & & \\
\hline & & & {$[0.021]^{* *}$} & & \\
\hline \multirow[t]{2}{*}{ Industry Output Growth Rate } & & & & 0.001 & \\
\hline & & & & {$[0.006]$} & \\
\hline \multirow[t]{2}{*}{ Unemployment Rate } & & & & & -2.131 \\
\hline & & & & & {$[0.19]^{* *}$} \\
\hline \multirow[t]{2}{*}{ Constant } & 4.49 & 4.52 & 2.52 & 4.48 & 4.81 \\
\hline & {$[0.014]^{* *}$} & {$[0.014]^{* *}$} & {$[0.319]^{* *}$} & {$[0.016]^{* *}$} & {$[0.026]^{* *}$} \\
\hline Observations & 86,176 & 73,701 & 86,160 & 80,346 & 86,176 \\
\hline R-squared & 0.80 & 0.82 & 0.81 & 0.81 & 0.81 \\
\hline
\end{tabular}

Dependent variable is Log (real wage rate). Real wage rate is the nominal wage rate deflated by the producer price index. Nominal wage rate is defined as the total wage bill/ number of employees. For each independent variable the first row gives the coefficient values and the second row gives the related t-values. All regressions include firm fixed effects. Standard errors are adjusted for clustering at the 4digit industry level. + significant at $10 \%$; ${ }^{*}$ significant at $5 \%$; ** significant at $1 \%$. 
Table A.2

Baseline Production Function Coefficient Estimates (Wooldridge 2009)

\begin{tabular}{|c|c|c|c|c|c|c|c|c|c|c|}
\hline Industry & Blue & White & Capital & Materials & Electricity & Services & $\mathrm{N}$ & $\begin{array}{l}\text { Sargan / } \\
\text { Hansen p- } \\
\text { value }\end{array}$ & $\begin{array}{l}\text { Returns to } \\
\text { scale (all } \\
\text { inputs) }\end{array}$ & $\begin{array}{l}\text { Returns to scale } \\
\text { (excluding } \\
\text { capital) }\end{array}$ \\
\hline (1) & $(2)$ & (3) & (4) & (5) & (6) & $(7)$ & (8) & (9) & $(10)$ & (11) \\
\hline 311 & 0.089 & 0.025 & 0.023 & 0.694 & 0.055 & 0.064 & 14,934 & 0.159 & 0.9492 & 0.9237 \\
\hline 313 & 0.153 & 0.033 & 0.058 & 0.450 & 0.114 & 0.125 & 1,228 & 0.142 & 0.9330 & 0.9004 \\
\hline 321 & 0.105 & 0.048 & 0.031 & 0.614 & 0.027 & 0.116 & 4,460 & 0.027 & 0.9412 & 0.8931 \\
\hline 322 & 0.105 & 0.060 & 0.070 & 0.615 & 0.034 & 0.084 & 3,598 & 0.567 & 0.9679 & 0.9076 \\
\hline 323 & 0.115 & 0.074 & 0.092 & 0.741 & 0.011 & 0.027 & 648 & 0.519 & 1.0610 & 0.9874 \\
\hline 324 & 0.150 & 0.060 & 0.022 & 0.575 & 0.042 & 0.083 & 1,684 & 0.583 & 0.9320 & 0.8721 \\
\hline 331 & 0.219 & 0.073 & 0.035 & 0.528 & 0.023 & 0.099 & 3,609 & 0.666 & 0.9765 & 0.9038 \\
\hline 342 & 0.056 & 0.074 & 0.067 & 0.418 & 0.066 & 0.141 & 2,084 & 0.584 & 0.8214 & 0.7477 \\
\hline 352 & 0.014 & 0.047 & 0.045 & 0.638 & 0.027 & 0.189 & 2,141 & 0.516 & 0.9601 & 0.9133 \\
\hline 355 & 0.296 & 0.050 & 0.065 & 0.403 & 0.010 & 0.099 & 718 & 0.128 & 0.9227 & 0.8731 \\
\hline 356 & 0.241 & 0.100 & 0.084 & 0.420 & 0.031 & 0.120 & 2,308 & 0.094 & 0.9953 & 0.8952 \\
\hline 362 & 0.155 & 0.098 & 0.079 & 0.466 & 0.096 & 0.077 & 256 & 0.483 & 0.9711 & 0.8732 \\
\hline 381 & 0.131 & 0.100 & 0.071 & 0.546 & 0.051 & 0.126 & 4,291 & 0.642 & 1.0244 & 0.9244 \\
\hline 383 & 0.149 & 0.014 & 0.022 & 0.580 & 0.025 & 0.168 & 638 & 0.353 & 0.9588 & 0.9445 \\
\hline 384 & 0.154 & 0.090 & 0.051 & 0.504 & 0.052 & 0.092 & 1,166 & 0.747 & 0.9437 & 0.8539 \\
\hline 390 & 0.214 & 0.007 & 0.008 & 0.504 & 0.020 & 0.125 & 664 & 0.033 & 0.8783 & 0.8716 \\
\hline
\end{tabular}

Production function coefficient estimates are from a gross output (revenue deflated by industry-specific deflators) Cobb-Douglas production function specification, which is estimated using Wooldridge (2009) modification of the Levinsohn-Petrin (2003) approach to address the simultaneous determination of inputs and productivity. 


\section{Table A.3}

The Absolute Value of the Gap

\section{Between the Value of Marginal Product and the Input Price, 1982-1994} Summary Statistics by Industry

\begin{tabular}{|c|c|c|c|c|c|c|c|c|c|c|}
\hline \multirow[b]{2}{*}{ Industry } & \multirow[b]{2}{*}{ Description } & \multicolumn{2}{|c|}{ Blue Collar } & \multicolumn{2}{|c|}{ White Collar } & \multicolumn{2}{|c|}{ Materials } & \multicolumn{2}{|c|}{ Electricity } & \multirow[b]{2}{*}{$\mathbf{N}$} \\
\hline & & Mean & SD & Mean & SD & Mean & SD & Mean & SD & \\
\hline 311 & Food products & 87.46 & 189.40 & 103.71 & 154.06 & 0.22 & 0.41 & 23.50 & 31.53 & 14859 \\
\hline 313 & Beverages & 289.26 & 292.47 & 160.97 & 183.57 & 0.39 & 0.46 & 59.56 & 51.87 & 1117 \\
\hline 321 & Textiles & 61.55 & 103.98 & 125.95 & 154.54 & 0.39 & 0.52 & 10.86 & 21.68 & 4241 \\
\hline 322 & Apparel (excl footwear) & 42.21 & 87.86 & 120.58 & 152.01 & 0.34 & 0.54 & 21.00 & 24.18 & 3532 \\
\hline 323 & Leather products & 93.40 & 129.51 & 222.92 & 252.75 & 0.25 & 0.37 & 5.10 & 14.58 & 623 \\
\hline 324 & Footwear & 53.53 & 98.53 & 130.19 & 140.45 & 0.21 & 0.23 & 27.01 & 32.04 & 1648 \\
\hline 331 & Wood products & 145.89 & 207.98 & 236.95 & 278.53 & 0.41 & 0.60 & 5.92 & 15.93 & 3622 \\
\hline 342 & Printing and publishing & 87.46 & 139.07 & 130.42 & 175.77 & 0.37 & 0.43 & 29.83 & 33.02 & 2073 \\
\hline 352 & Other chemicals & 67.07 & 63.33 & 226.26 & 200.02 & 0.39 & 0.50 & 28.81 & 33.85 & 2006 \\
\hline 355 & Rubber products & 260.83 & 280.14 & 111.99 & 145.95 & 0.38 & 0.37 & 2.28 & 8.54 & 678 \\
\hline 356 & Plastic products & 234.90 & 256.37 & 267.45 & 287.03 & 0.34 & 0.28 & 7.68 & 21.20 & 2293 \\
\hline 362 & Glass products & 154.80 & 245.82 & 226.91 & 274.01 & 0.82 & 0.92 & 31.06 & 47.07 & 215 \\
\hline 381 & Fabricated metal products & 87.24 & 162.25 & 219.51 & 273.50 & 0.36 & 0.49 & 20.11 & 28.90 & 4308 \\
\hline 383 & Electrical machinery & 178.82 & 264.15 & 196.88 & 165.42 & 0.46 & 0.59 & 13.14 & 21.92 & 650 \\
\hline 384 & Transport equipment & 121.26 & 232.84 & 213.26 & 285.85 & 0.52 & 0.60 & 22.13 & 33.40 & 1184 \\
\hline 390 & Other manufactured products & 109.57 & 132.79 & 121.44 & 110.27 & 0.74 & 0.85 & 9.09 & 16.46 & 626 \\
\hline Overall & & 102.50 & 186.70 & 154.71 & 207.24 & 0.33 & 0.49 & 20.09 & 30.40 & 43675 \\
\hline
\end{tabular}

All gaps are in thousands of 1979 pesos (deflator used is the CPI). Marginal product estimates are from a gross output (revenue deflated by industry-specific deflators) Cobb-Douglas production function specification, which is estimated using Wooldridge (2009) modification of the Levinsohn-Petrin (2003) approach to address the simultaneous determination of inputs and productivity. The blue-collar input price is the total blue-collar wage bill divided by the number of blue-collar employees. We define the white collar input price similarly. For materials we use a 3digit industry-specific price index. Electricity prices are derived from establishment-specific quantity and value information. We estimate production functions separately for each 3-digit industry. 


\section{Table A.4}

The Gap between the Value of Marginal Product and the Wages, 1982-1994

Sample-splitting Test based on Industry Unionization Rate

Simultaneity-Corrected Production Function Estimates, All Specifications include Plant Fixed Effects

\begin{tabular}{|c|c|c|c|c|c|c|c|c|}
\hline & \multicolumn{2}{|c|}{ Blue Collar } & \multicolumn{2}{|c|}{ White Collar } & \multicolumn{2}{|c|}{ Materials } & \multicolumn{2}{|c|}{ Electricity } \\
\hline & $\begin{array}{l}\text { Above } \\
\text { median }\end{array}$ & $\begin{array}{l}\text { Below } \\
\text { median }\end{array}$ & $\begin{array}{l}\text { Above } \\
\text { median }\end{array}$ & $\begin{array}{c}\text { Below } \\
\text { median }\end{array}$ & $\begin{array}{l}\text { Above } \\
\text { median }\end{array}$ & $\begin{array}{l}\text { Below } \\
\text { median }\end{array}$ & $\begin{array}{l}\text { Above } \\
\text { median }\end{array}$ & $\begin{array}{l}\text { Below } \\
\text { median }\end{array}$ \\
\hline & (1a) & $(1 \mathrm{~b})$ & $(2 a)$ & $(2 \mathrm{~b})$ & (3a) & $(3 b)$ & $(4 a)$ & $(4 \mathrm{~b})$ \\
\hline Base Period Gap (1982-1984) & $\begin{array}{r}91.18^{* * *} \\
{[7.686]}\end{array}$ & $\begin{array}{r}71.89 * * * \\
{[7.777]}\end{array}$ & $\begin{array}{r}136.5^{* * *} \\
{[4.652]}\end{array}$ & $\begin{array}{r}140.1^{* * *} \\
{[8.580]}\end{array}$ & $\begin{array}{l}0.289^{* * *} \\
{[0.0138]}\end{array}$ & $\begin{array}{l}0.421^{* * *} \\
{[0.0141]}\end{array}$ & $\begin{array}{r}25.87^{* * *} \\
{[0.771]}\end{array}$ & $\begin{array}{r}18.13^{* * *} \\
{[0.933}\end{array}$ \\
\hline Increase in Gap, 2nd Pd. (85-90) & $\begin{array}{r}12.59 \\
{[12.00]}\end{array}$ & $\begin{array}{r}26.63^{* * *} \\
{[7.732]}\end{array}$ & $\begin{array}{r}2.943 \\
{[7.590]}\end{array}$ & $\begin{array}{r}30.47^{* * *} \\
{[10.60]}\end{array}$ & $\begin{array}{r}-0.021 \\
{[0.0177]}\end{array}$ & $\begin{array}{r}-0.0547^{* * *} \\
{[0.0179]}\end{array}$ & $\begin{array}{r}-3.040^{* * *} \\
{[1.027]}\end{array}$ & $\begin{array}{r}0.68 \\
{[0.982}\end{array}$ \\
\hline Increase in Gap, 3rd Pd. (91-94) & $\begin{array}{r}8.876 \\
{[7.902]}\end{array}$ & $\begin{array}{r}38.22^{* * *} \\
{[13.31]}\end{array}$ & $\begin{array}{r}3.893 \\
{[5.319]}\end{array}$ & $\begin{array}{r}44.05^{* * *} \\
{[12.59]}\end{array}$ & $\begin{array}{l}-0.0345^{*} \\
{[0.0182]}\end{array}$ & $\begin{array}{r}-0.0265 \\
{[0.0186]}\end{array}$ & $\begin{array}{r}-6.187^{* * *} \\
{[1.125]}\end{array}$ & $\begin{array}{r}0.406 \\
{[1.417}\end{array}$ \\
\hline Industry Output Growth Rate & $\begin{array}{l}20.38^{* *} \\
{[8.060]}\end{array}$ & $\begin{array}{r}0.342 \\
{[0.854]}\end{array}$ & $\begin{array}{r}29.12^{* * *} \\
{[9.190]}\end{array}$ & $\begin{array}{r}-0.664 \\
{[1.258]}\end{array}$ & $\begin{array}{r}-0.0161 \\
{[0.0103]}\end{array}$ & $\begin{array}{r}-0.00358 \\
{[0.0194]}\end{array}$ & $\begin{array}{r}5.342^{* * *} \\
{[1.634]}\end{array}$ & $\begin{array}{r}0.448 \\
{[0.477]}\end{array}$ \\
\hline Observations & 21,990 & 19,519 & 21,990 & 19,519 & 21,990 & 19,519 & 21,990 & 19,519 \\
\hline R-squared & 0.827 & 0.747 & 0.669 & 0.65 & 0.516 & 0.492 & 0.554 & 0.631 \\
\hline
\end{tabular}

Unionization rate is defined at the 3-digit industry level using data on employment history and union status in the Social Protection Survey dataset for 2009 (accessed at http:/ / www. proteccionsocial.cl/). All gaps are in thousands of 1979 pesos (deflator used is the CPI). Marginal product estimates are from a gross output Cobb-Douglas production function specification, which is estimated using Wooldridge (2009) modification of the Levinsohn-Petrin (2003) approach to address the simultaneous determination of inputs and productivity. See notes to Table 1 for definitions of input prices. Standard errors (reported in brackets) are clustered at the 4-digit industry level. * significant at $10 \%$; ** significant at $5 \%$; *** significant at $1 \%$. 
Table A.5

The Absolute Value of the Gap

Between the Value of Marginal Product and the Input Price, 1982-1994

Robustness to alternative (GDP) deflator

Simultaneity-Corrected Production Function Estimates, All Specifications include Firm Fixed Effects

\begin{tabular}{|c|c|c|c|c|c|c|c|c|}
\hline & \multicolumn{2}{|c|}{ Blue Collar } & \multicolumn{2}{|c|}{ White Collar } & \multicolumn{2}{|c|}{ Materials } & \multicolumn{2}{|c|}{ Electricity } \\
\hline & $(1)$ & $(2)$ & (3) & $(4)$ & $(5)$ & $(6)$ & $(7)$ & $(8)$ \\
\hline Base Period Gap (1982-1984) & $\begin{array}{r}93.86^{* * *} \\
{[6.810]}\end{array}$ & $\begin{array}{r}94.28^{* * *} \\
{[6.816]}\end{array}$ & $\begin{array}{r}155.7^{* * *} \\
{[5.709]}\end{array}$ & $\begin{array}{r}156.1^{* * *} \\
{[5.659]}\end{array}$ & $\begin{array}{l}0.400^{* * *} \\
{[0.0117]}\end{array}$ & $\begin{array}{l}0.400^{* * *} \\
{[0.0118]}\end{array}$ & $\begin{array}{r}23.68^{* * *} \\
{[1.000]}\end{array}$ & $\begin{array}{r}23.81^{* * *} \\
{[1.004]}\end{array}$ \\
\hline Increase in Gap, 2nd Pd. (85-90) & $\begin{array}{l}22.09^{* *} \\
{[8.804]}\end{array}$ & $\begin{array}{l}21.51^{* *} \\
{[8.765]}\end{array}$ & $\begin{array}{c}14.28^{*} \\
{[7.650]}\end{array}$ & $\begin{array}{c}13.74^{*} \\
{[7.507]}\end{array}$ & $\begin{array}{r}-0.0561^{* * *} \\
{[0.0171]}\end{array}$ & $\begin{array}{r}-0.0549 * * * \\
{[0.0172]}\end{array}$ & $\begin{array}{r}-1.326 \\
{[1.118]}\end{array}$ & $\begin{array}{r}-1.51 \\
{[1.121]}\end{array}$ \\
\hline Increase in Gap, 3rd Pd. (91-94) & $\begin{array}{l}25.11^{* *} \\
{[9.524]}\end{array}$ & $\begin{array}{l}24.57^{* *} \\
{[9.566]}\end{array}$ & $\begin{array}{l}21.69^{* *} \\
{[8.392]}\end{array}$ & $\begin{array}{l}21.20^{* *} \\
{[8.403]}\end{array}$ & $\begin{array}{r}-0.0456^{* * *} \\
{[0.0136]}\end{array}$ & $\begin{array}{r}-0.0446^{* * *} \\
{[0.0139]}\end{array}$ & $\begin{array}{r}-3.047^{* *} \\
{[1.515]}\end{array}$ & $\begin{array}{r}-3.217^{* *} \\
{[1.524]}\end{array}$ \\
\hline Industry Output Growth Rate & & $\begin{array}{r}2.684 \\
{[2.274]}\end{array}$ & & $\begin{array}{r}2.444 \\
{[2.467]}\end{array}$ & & $\begin{array}{r}-0.0053 \\
{[0.0153]}\end{array}$ & & $\begin{array}{r}0.843 \\
{[0.642]}\end{array}$ \\
\hline Observations & 43,675 & 43,675 & 43,675 & 43,675 & 43,675 & 43,675 & 43,675 & 43,675 \\
\hline R-squared & 0.792 & 0.792 & 0.653 & 0.653 & 0.504 & 0.504 & 0.589 & 0.589 \\
\hline
\end{tabular}

The deflator used is the GDP deflator (World Bank WDI). Marginal product estimates are from a gross output (revenue deflated by industryspecific deflators) Cobb-Douglas production function specification, which is estimated using Wooldridge (2009) modification of the LevinsohnPetrin (2003) approach to address the simultaneous determination of inputs and productivity. The blue-collar input price is the total blue-collar wage bill divided by the number of blue-collar employees. We define the white collar input price similarly. For materials we use a 3-digit industry-specific price index. Electricity prices are derived from establishment-specific quantity and value information. We estimate production functions separately for each 3-digit industry. Standard errors (reported in brackets) are clustered at the 4-digit industry level. * significant at 10\%; ** significant at $5 \%$; ${ }^{* * *}$ significant at $1 \%$. 
Table A.6

The Gap between the Value of Marginal Product and the Input Price, 1982-1994

Robustness to using Balanced Panels

Simultaneity-Corrected Production Function Estimates, All Specifications include Plant Fixed Effects

\begin{tabular}{|c|c|c|c|c|c|c|c|c|}
\hline & \multicolumn{4}{|c|}{ Balanced Panel 1} & \multicolumn{4}{|c|}{ Balanced Panel 2} \\
\hline & \multicolumn{2}{|c|}{ Blue Collar White Collar } & \multirow{2}{*}{$\begin{array}{r}\text { Materials } \\
(3) \\
\end{array}$} & \multirow{2}{*}{$\begin{array}{r}\text { Electricity } \\
(4) \\
\end{array}$} & \multicolumn{2}{|c|}{ Blue Collar White Collar } & \multirow{2}{*}{$\begin{array}{r}\text { Materials } \\
(7) \\
\end{array}$} & \multirow{2}{*}{$\begin{array}{r}\text { Electricity } \\
(8)\end{array}$} \\
\hline & $(1)$ & $(2)$ & & & $(5)$ & $(6)$ & & \\
\hline \multirow[t]{2}{*}{ Base Period Gap (1982-1984) } & $92.71^{* * *}$ & $135.7^{* * *}$ & $0.342^{* * *}$ & $20.15^{\star \star *}$ & $88.44^{* * *}$ & $133.3^{* * *}$ & $0.335^{* * *}$ & $20.72^{* * *}$ \\
\hline & {$[7.377]$} & {$[5.764]$} & [0.0102] & {$[0.908]$} & [6.923] & [5.667] & [0.00954] & [0.958] \\
\hline \multirow[t]{2}{*}{ Increase in Gap, 2nd Pd. (85-90) } & $27.14^{* * *}$ & $18.72^{* *}$ & $-0.0457^{* * *}$ & -0.852 & $24.82^{* *}$ & $19.02^{* *}$ & $-0.0373^{* *}$ & -0.689 \\
\hline & {$[9.805]$} & [7.928] & [0.0145] & [1.041] & [9.365] & [7.867] & [0.0141] & [1.114] \\
\hline \multirow[t]{2}{*}{ Increase in Gap, 3rd Pd. (91-94) } & $30.33^{* * *}$ & $27.13^{* * *}$ & $-0.0345^{* * *}$ & -1.261 & $27.58^{* * *}$ & $25.70^{* * *}$ & $-0.0257^{* *}$ & -1.48 \\
\hline & {$[10.15]$} & [8.450] & [0.0128] & [1.432] & [9.406] & [8.259] & [0.0114] & [1.485] \\
\hline \multirow[t]{2}{*}{ Industry Output Growth Rate } & 2.471 & 2.099 & -0.0104 & 0.593 & 2.832 & 2.541 & -0.0125 & 0.65 \\
\hline & [1.985] & {$[2.063]$} & [0.00823] & [0.431] & [2.190] & [2.378] & [0.00951] & [0.461] \\
\hline Observations & 22,923 & 22,923 & 22,923 & 22,923 & 26,928 & 26,928 & 26,928 & 26,928 \\
\hline R-squared & 0.788 & 0.606 & 0.427 & 0.548 & 0.783 & 0.603 & 0.425 & 0.537 \\
\hline
\end{tabular}

All gaps are in thousands of 1979 pesos (deflator used is the CPI). In columns 1-4 (Balanced Panel 1), we use only those plants that have at least two observations in the base period (1982-1984), all six observations for the $2^{\text {nd }}$ period (85-90) and at least two observations for the third period (91-94). In columns 5-8 (Balanced Panel 2), we use only those plants that have at least two observations in each of the three periods. Marginal product estimates are from a gross output (revenue deflated by industry-specific deflators) Cobb-Douglas production function specification, which is estimated using Wooldridge (2009) modification of the Levinsohn-Petrin (2003) approach to address the simultaneous determination of inputs and productivity. The blue-collar input price is the total blue-collar wage bill divided by the number of blue-collar employees. We define the white collar input price similarly. For materials we use a 3-digit industry-specific price index. Electricity prices are derived from establishment-specific quantity and value information. We estimate production functions separately for each 3-digit industry. Standard errors (reported in brackets) are clustered at the 4-digit industry level. * significant at $10 \%$; ** significant at $5 \%$; *** significant at $1 \%$. 


\section{Table A.7}

\section{Effect of gap on exit hazard/propensity}

\begin{tabular}{|c|c|c|c|c|c|c|c|c|}
\hline splui & $\begin{array}{c}(1) \\
\text { streg }\end{array}$ & $\begin{array}{c}(2) \\
\text { streg }\end{array}$ & $\begin{array}{l}(3) \\
\text { ols }\end{array}$ & $\begin{array}{l}(4) \\
\text { ols }\end{array}$ & $\begin{array}{c}(5) \\
\text { streg } \\
\end{array}$ & $\begin{array}{c}(6) \\
\text { streg } \\
\end{array}$ & $\begin{array}{l}(7) \\
\text { ols }\end{array}$ & $\begin{array}{l}(8) \\
\text { ols }\end{array}$ \\
\hline Absolute blue collar gap & $0.000952^{* * *}$ & & $3.79 \mathrm{e}-05^{* * *}$ & & & & & \\
\hline \multirow[t]{2}{*}{ Absolute blue collar gap X D_(Blue gap >0) } & & $0.000881^{* * *}$ & & $3.66 \mathrm{e}-05^{* * *}$ & & & & \\
\hline & & [0.000192] & & [1.35e-05] & & & & \\
\hline Absolute blue collar gap X D_(Blue gap <=0) & & $0.00403^{* * *}$ & & $0.000159^{* * *}$ & & & & \\
\hline \multirow[t]{2}{*}{ Absolute white collar gap } & & & & & 0.000215 & & $1.80 \mathrm{e}-05^{\star * *}$ & \\
\hline & & & & & [0.000185] & & {$[4.53 \mathrm{e}-06]$} & \\
\hline \multirow[t]{2}{*}{ Absolute white collar gap X D_(White gap >0) } & & & & & & 0.000153 & & $1.69 \mathrm{e}-05^{* * *}$ \\
\hline & & & & & & $.000196]$ & & [3.99e-06] \\
\hline Absolute white collar gap X D_(White gap $<=0$ ) & & & & & & $000741^{*}$ & & $3.19 \mathrm{e}-05^{*}$ \\
\hline Observations & 43,680 & 43,680 & 43,680 & 43,680 & 43,680 & 43,680 & 43,680 & 43,680 \\
\hline Effect of a one SD change on: & $\begin{array}{l}\text { Hazard } \\
\text { rate }\end{array}$ & $\begin{array}{l}\text { Hazard } \\
\text { rate }\end{array}$ & $\begin{array}{c}\text { Exit } \\
\text { propensity }\end{array}$ & $\begin{array}{c}\text { Exit } \\
\text { propensity }\end{array}$ & $\begin{array}{l}\text { Hazard } \\
\text { rate }\end{array}$ & $\begin{array}{l}\text { Hazard } \\
\text { rate }\end{array}$ & $\begin{array}{c}\text { Exit } \\
\text { propensity }\end{array}$ & $\begin{array}{c}\text { Exit } \\
\text { propensity }\end{array}$ \\
\hline Absolute blue collar gap (SD: 218.65) & 1.1945 & & 0.0071 & & & & & \\
\hline Absolute positive blue collar gap (SD: 220.97) & & 1.1830 & & 0.0070 & & & & \\
\hline Absolute negative blue collar gap (SD: 18.49) & & 1.1169 & & 0.0044 & & & & \\
\hline Absolute white collar gap (SD: 187.98) & & & & & 1.0456 & & 0.0037 & \\
\hline Absolute positive white collar gap (SD: 183.66) & & & & & & 1.0324 & & 0.0035 \\
\hline Absolute negative white collar gap (SD: 96.07) & & & & & & 1.0726 & & 0.0030 \\
\hline
\end{tabular}

Columns 1,2 5 and 6 are ML regression survival-time (exponential) models. Columns 2, 3, 7 and 8 are linear exit models (with the dependent variable an exit dummy $=1$ if the plant exits from the sample in that year). The gaps are estimated as in Table 1 (see notes). Standard errors (reported in brackets) are clustered at the 4-digit industry level. * significant at $10 \%$; ${ }^{* *}$ significant at $5 \%$; ${ }^{* * *}$ significant at $1 \%$. 